\title{
Comunidad de hongos filamentosos en suelos del Agroecosistema de K'iphak'iphani, Comunidad Choquenaira-Viacha
}

\author{
Filamentous soil fungi comunities on K'iphak'iphani agroesosistems,
} Choquenaira-Viacha Municipaly

\author{
Pacasa-Quisbert Fernando ${ }^{1 *}$, Loza-Murguia Manuel Gregorio ${ }^{2,3}$, Bonifacio-Flores Alejandro ${ }^{1}$, \\ Vino-Nina Lourdes ${ }^{1}$, Serrano-Canaviri Teófilo ${ }^{1}$
}

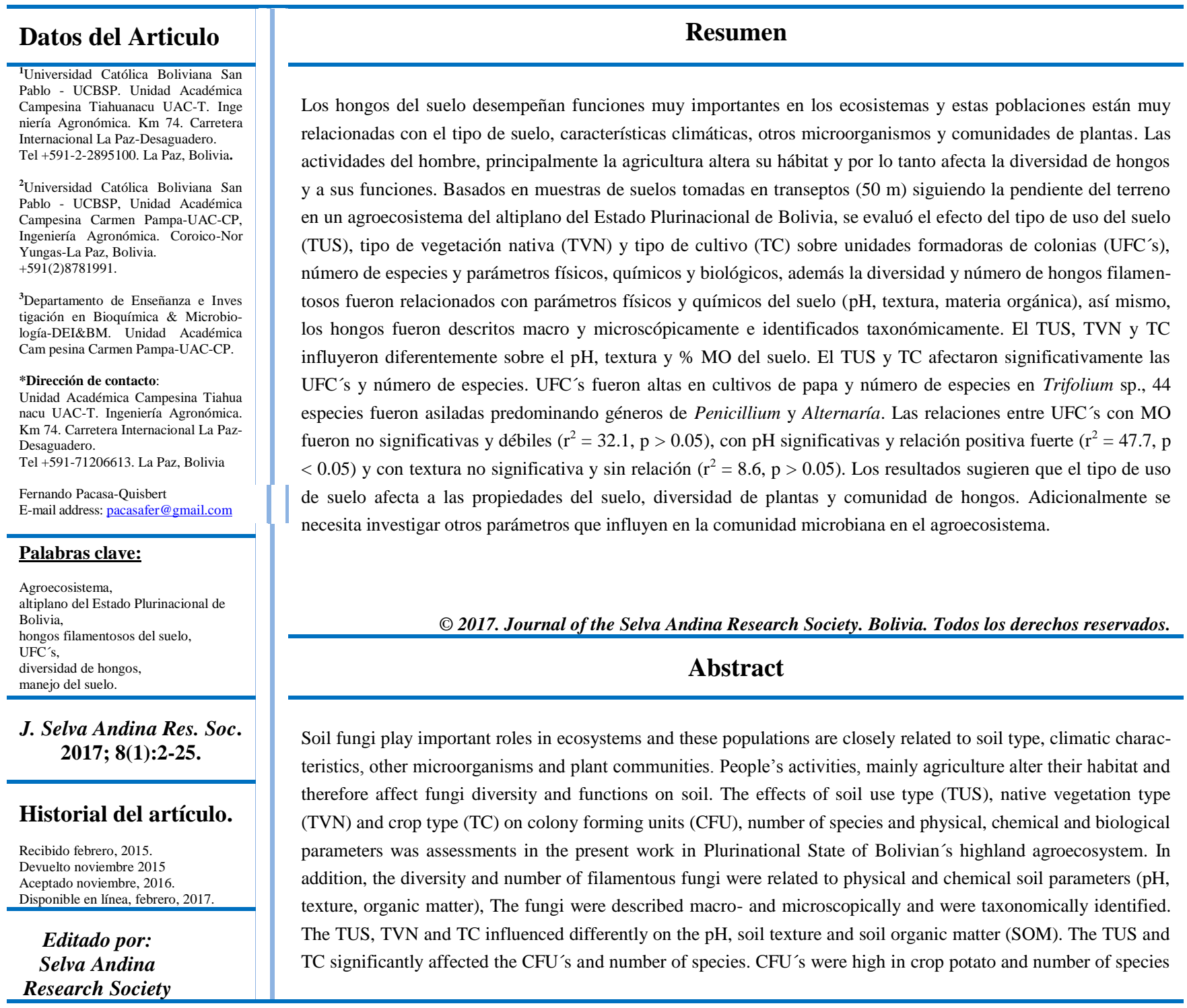




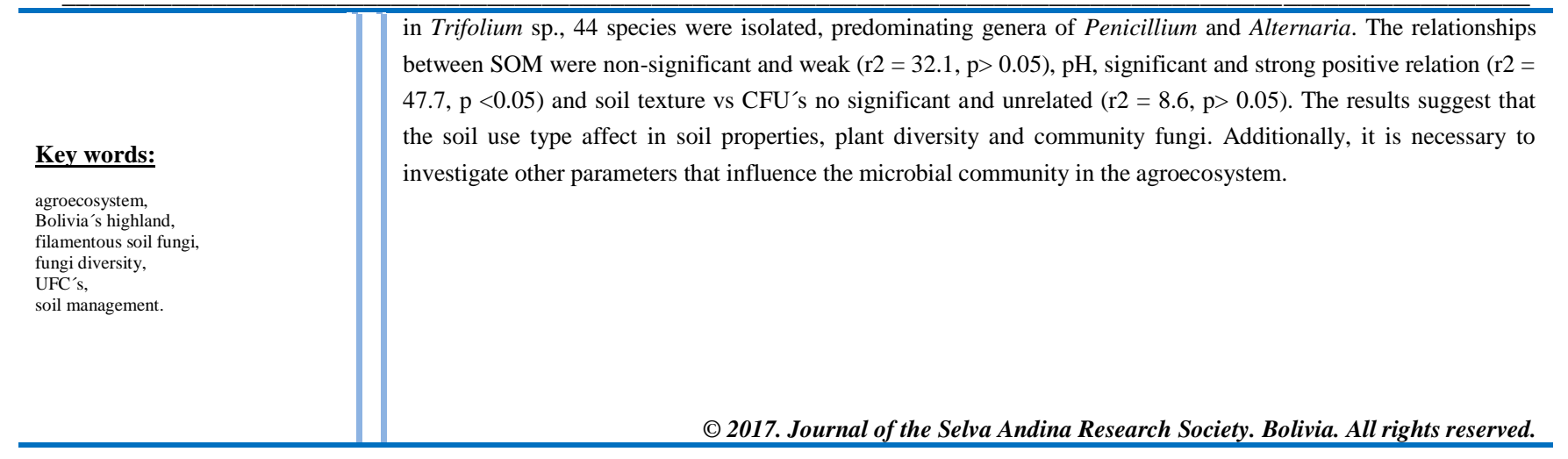

\section{Introducción}

El suelo es un ambiente complejo que ofrece una alta variedad de microhábitats para la gran biodiversidad microbiana de diversos grupos de microorganismos, como virus, bacterias, actinomicetos, hongos, algas y protozoos (Webster \& Weber 2007, Moreira \& Siquiera 2006). Las bacterias representan en general el mayor número, en cambio los hongos el mayor porcentaje de la biomasa microbiana de los suelos. Las bacterias y hongos, integrantes más estudiados en relación a otras comunidades de microorganismos (Coyne 2000). Los hongos del suelo de regiones áridas, semiáridas, hasta en regiones tropicales no han sido estudiados ampliamente (Christensen 1969, Flanagan 1981, Domsch et al. 1980). En zonas áridas son característicos los hongos de los géneros Aspergillus y Penicillium (Flanagan 1981) Penicillium es abundante en temperaturas y climas fríos, mientras Aspergillus predominan en climas templados, sin embargo todos los hongos son regulados por la cantidad y calidad del sustrato (Paul 2007), se han detectado géneros de Beauveria y Metarhizium distribuidos en el altiplano central de La Paz (Rojas-Gutiérrez 2014).

La mayor abundancia de hongos se hallan en las capas u horizontes superficiales del suelo, donde el microclima, ambiente y disponibilidad de recursos

3 nutricionales son favorables para el desarrollo y crecimiento de hongos (Lavelle \& Spain 2001), pero escasos a causa de la compactación de los suelos, agricultura convencional y aplicación de sustancias químicas (Coyne 2000).

El tipo de uso del suelo (TUS) tiene efectos considerables sobre la diversidad de plantas (DeFries et al. 2004), que al establecer relaciones con las comunidades de hongos, disminuye la diversidad y abundancia de estos hongos por los daños ocasionados (Sivila \& Hervé 1999, Cabello \& Arambarri 2002).

La diversidad biológica de hongos en Bolivia son escasamente documentados (Arias-Mota et al. 2007), así como también de las relaciones que podrían existir entre la diversidad de hongos y micorrizas con algunas características del suelo y recuperación de la fertilidad de los suelos en el altiplano central de Bolivia (Sivila \& Hervé 1999, Sivila de Cary \& Angulo 2006).

El agroecosistema en estudio K'iphak'iphani, ubicado en el altiplano central boliviano, comprende una región con diferentes manejos de suelos destinados a la producción agrícola en rotación y producción ganadera. Las características del suelo están 
condicionadas de acuerdo al tipo de uso, existiendo zonas marcadas por esta causa.

Los objetivos del presente trabajo fueron: $i$ ) determinar el efecto del tipo de manejo del suelo, tipo de cultivo y tipo de vegetación nativa sobre la diversidad y abundancia de hongos filamentosos en suelos, ii) establecer relaciones entre las propiedades del suelo con UFC's de hongos, y iii) caracterizar la diversidad de hongos del suelo en el agroecosistema de K'iphak'iphani, comunidad Choquenaira-Viacha, departamento de La Paz. Este estudio fue realizado en el periodo de verano austral desde diciembre a enero, cuando las condiciones climáticas son favorables para el desarrollo de los cultivos, vegetación nativa y microorganismos.

\section{Materiales y métodos}

Área de estudio y clima regional. El área de estudio está localizada en el centro del altiplano boliviano (Municipio de Viacha, Provincia Ingávi, Departamento de La Paz-Estado Plurinacional de Bolivia), ubicada geográficamente entre las coordenadas $16^{\circ}$ $39^{\prime} 47^{\prime \prime}$ latitud sur y $68^{\circ} 18^{\prime} 16^{\prime \prime}$ latitud oeste con una altitud promedio de $3885 \mathrm{msnm}$. En general, comprende el clima propio del altiplano central boliviano con temperaturas medias de $8.41{ }^{\circ} \mathrm{C}$, máximas de $17.45{ }^{\circ} \mathrm{C}$ y mínimas de $1{ }^{\circ} \mathrm{C}$, precipitaciones anuales de $524 \mathrm{~mm}$, humedad relativa media anual de $72 \%$. Presenta una distribución normal de una estación seca desde abril a octubre y estación húmeda de noviembre a marzo. PDM Viacha 2012). Caracterización del agroecosistema. La caracterización de las propiedades físicas, químicas y biológicas del agroecosistema fue realizada para establecer factores que afectan a la distribución de los hongos del suelo, fueron caracterizados el tipo de uso del suelo, vegetación nativa y cultivo estableci- do, factores físicos y químicos. Los datos de $\mathrm{pH}$, materia orgánica (MO) (\%), Conductividad eléctrica (CE) y textura del suelo (TS), \% de arena (A) fueron análisis de las muestras de suelo en un laboratorio de especialidad Instituto Boliviano de Tecnologia Nuclear (IBTEN).

Muestreo de suelos. Los sitios de muestreos fueron clasificados con las recomendaciones de Bills et al. (2004) divididos en tres factores e independientes con diferentes tratamientos, $i$ ) Tipo de uso del suelo (TUS: suelos con cultivo, suelos en descanso, suelos naturales y suelos sin cobertura), ii) Tipo de cultivo (TC: cultivo quinua, papa y cebada) y iii) Tipo de vegetación nativa (TVN: sitios vegetales de Festuca sp., Trifolium sp., Herodium sp., y Distichlis sp.) que existen en el agroecosistema, previó historial del lugar y diagnóstico en campo.

La disposición de los muestreos fue de acuerdo a transeptos de $50 \mathrm{~m}$ siguiendo la pendiente del terreno, en cada punto de muestreo se acopiaron 6 submuestras para formar una muestra compuesta de suelo de una parcela, las muestras fueron tomadas a una profundidad de 0 a $15 \mathrm{~cm}$, a razón de 400 a 500 $\mathrm{g}$ de suelo, empleándose un extractor de núcleo en suelos suaves, o pala y picota en suelos duros o con rocas, para cada muestreo los materiales fueron desinfectados sumergiéndolos en un recipiente que contenía solución de hipoclorito al 10\%, para el manipuleo de los materiales y muestreo se usó guantes descartables evitándose toda posible contaminación. A continuación fueron almacenadas en bolsas plásticas estériles, llevadas en una caja de almacenamiento, seguidamente fueron transportadas al laboratorio para procesarlas el mismo día.

Aislamiento de hongos. De la cantidad total de muestra se separó $100 \mathrm{~g}$ de suelo tamizado, inmediatamente fueron procesadas mediante tres técnicas de aislamiento para el conteo de unidades formado- 
ras de colonias (UFC's) y obtención de máximos aislamientos de hongos filamentosos desde el suelo. Para los aislamientos de hongos filamentosos del suelo se empleó los métodos: i) Dilución en placas, ii) Siembra directa (Bills et al. 2004), iii) Placas de suelo (Warcup 1950), que fueron extendidas sobre la superficie de los medios de cultivo papa dextrosa agar (PDA), hongos levaduras papa (HLP), harina maíz papa (HMA), agar extracto de suelo (AES) y sabouraud agar (SA) adicionando cloranfenicol a razón de $0.05 \mathrm{mg} \mathrm{mL}^{-1}$ para evitar el crecimiento bacteriano en las cajas Petri, finalmente se llevó las placas Petri a incubación por tres a siete días a $22^{\circ} \mathrm{C}$ para posterior recuento de colonias y obtención de cultivos puros.

Recuento y aislamiento a cultivos puros. El recuento UFC's después de 5 días de incubación, en siembras con medio PDA, fueron numerados las colonias donde tuvieron un crecimiento entre 30 a 300 UFC's, empleando la ecuación de recuento en placa se expresó en unidades formadoras de colonias por gramo de suelo (UFC's g ${ }^{-1}$ ) para posterior análisis estadístico (Bills et al. 2004).

Los aislamientos realizados de las diferentes muestras de suelos mediante las tres técnicas y los cinco medios de cultivo, fueron utilizados para el aislamiento a cultivos puros. Después del periodo de incubación (3 a 5 días), se observó el crecimiento de diferentes UFC's, posteriormente de acuerdo al color, forma, con un aza bacteriológica se hizo el repique a un medio definitivo (PDA) e incubadas por 4 días a $25{ }^{\circ} \mathrm{C}$. Durante este periodo fueron aislándose entre aquellas UFC's que presentaban semejanza en su crecimiento, color, forma dentro y fuera de la caja Petri para que no existieran cultivos puros repetidos.

Descripción macro y microscópicas. Las características macroscópicas de las UFC's se describieron 5 según Watanabe (2010), fueron descritos a los siete días después de la incubación por el anverso y reverso que presentaban las UFC's en caja Petri, por Anverso, de acuerdo a las características del cultivo como: i) color de la superficie y contorno de la colonia, ii) textura, iii) color del pigmento exudado y $i v$ ) forma de la colonia y del margen, Reverso, de acuerdo $i$ ) al color de la parte interior, media y borde de la colonia, ii) superficie interior y iii) exterior de la colonia.

Para observaciones preliminares del hongo filamentosos al microscopio, se empleó la técnica de la cinta pegante (Díaz et al. 1999), que consiste en extraer fragmentos de la colonia presionando suavemente el lado pegante de la cinta sobre el micelio aéreo del hongo y poner la cinta sobre porta objetos con una gota de azul de lactofenol y observar al microscopio las características morfológicas del micelio y órganos reproductivos con aumentos de 40X para su identificación taxonómica de género.

La identificación de géneros de hongos filamentosos fue realizada con la técnica de micro cultivo (Díaz et al. 1999), posteriormente se observó al microscopio las estructuras de los hongos filamentosos, se fotografío el micelio y estructuras reproductivas, las fotografías fueron comparadas con descripciones originales. Las identificaciones taxonómicas presumibles de los géneros de hongos filamentosos fue tomando en cuenta las características microscópicas, luego se comparó con la literatura de claves taxonómicas de Barnett \& Hunter 1998, Kirk et al. 2008, Watanabe 2010, Samson et al. 2014. Aquellas no identificados fueron denominados como cepas no tipificadas.

Análisis de datos e interacciones. El análisis de los datos fue a través de un diseño experimental completamente al azar y con tres repeticiones por tratamiento, los factores en estudio se evaluaron por 
separado y no hubo interacción entre estos, cada factor fue independiente. Las comparaciones entre medias se efectuaron con la prueba de medias de Duncan con nivel de significancia del 5\%. Las variables de respuesta para determinar el efecto del TUS, TC y TVN fueron $i$ ) Número de especies de hongos filamentosos (unidades), ii) Unidades formadoras de colonias de hongos por gramo de suelo (UFC's g de suelo ${ }^{-1}$ ).

Los datos de $\mathrm{pH}, \mathrm{MO}(\%)$ y TS (\% de A), fueron confrontados con la abundancia de hongos filamentosos mediante un análisis estadístico de regresión lineal simple. Además se emplearon el coeficiente de correlación de Pearson y de determinación, para medir el grado de relación entre las variables.

\section{Resultados}

\section{Características del agroecosistema}

Topografía y climatología. El agroecosistema de $\mathrm{K}^{\prime}$ 'iphak`iphani está localizada entre los paralelos $16^{\circ} 39^{\prime} 30^{\prime \prime}$ a $16^{\circ} 40^{\prime} 42^{\prime \prime}$ latitud sur y $68^{\circ} 18^{\prime} 05^{\prime \prime}$ a $68^{\circ} 17^{\prime} 18^{\prime \prime}$ longitud oeste. La topografía está integrada por planicies, laderas y cumbres de cerros con ondulaciones anchas y suaves. Tiene una altitud media de 3853 msnm (ladera) y 3947 msnm (cumbre). El régimen climatológico se caracteriza por dos estaciones diferentes, precipitaciones en estación lluviosa (noviembre-marzo) y posteriormente van reduciéndose y dan paso a la estación seca (mayo-octubre), la precipitación promedio anual es de $494 \mathrm{~mm}$, temperatura promedio de $9.56{ }^{\circ} \mathrm{C}$, mínima y máxima de -12 a $17^{\circ} \mathrm{C}$ y humedad relativa del $55 \%$.

Uso del suelo. El uso del suelo dentro del agroecosistema son: $i$ ) suelos productivos mayormente ubicados en la planicie, con cultivos como quinua, cebada, avena y papa que se basan en la rotación de cultivos y del suelo con periodos de descanso de 3 a 5 años (suelos en descanso), en donde la vegetación nativa nuevamente vuelve a poblar el terreno después del ciclo agrícola con labranza y siembra mecanizada, ii) suelos sin intervención (naturales), ubicados en las laderas de los cerros planicies,

Tabla 1 Propiedades físico-químico y materia orgánica de acuerdo al tipo de: uso de suelo, cultivo y vegetación nativa en el agroecosistema K'iphak'iphani

\begin{tabular}{llcrr}
\hline \multicolumn{1}{c}{ Factor } & \multicolumn{1}{c}{ Textura } & pH & CE dS m- & MO \% \\
\hline Tipo de uso de Suelo & & & & \\
\cline { 1 - 2 } Suelo natural & Franco arcilloso & 7.23 & 0.08 & 5.38 \\
Suelos en descanso & Arcilloso & 7.41 & 0.15 & 1.01 \\
Suelos con cultivo & Franco arcilloso arenoso & 7.56 & 0.18 & 0.87 \\
Suelos sin cobertura & Arcilloso & 6.86 & 0.14 & 0.7 \\
Tipo de cultivo & & & & \\
\hline Cultivo quinua & Franco arcilloso arenoso & 7.89 & 0.21 & 0.78 \\
Cultivo cebada & Franco arcilloso arenoso & 7.25 & 0.13 & 1.41 \\
Cultivo papa & Franco arcilloso & 7.36 & 0.11 & 1.87 \\
Tipo de vegetación nativa & & & & \\
\hline Festuca sp. & Arcilloso & 7.06 & 0.05 & 8.97 \\
Herodium sp. & Franco arcilloso & 6.65 & 0.07 & 5.62 \\
Distichlis sp. & Arcilloso & 6.86 & 0.03 & 5.07 \\
Trifolium sp. & Franco arcilloso arenoso & 7.26 & 0.03 & 1.72 \\
\hline
\end{tabular}


formado por una capa superficial de suelo no profunda de 5 a $10 \mathrm{~cm}$ y por debajo roca (cerro) y suelos profundos de 30 a 60 (planicies), destinados principalmente al pastoreo ya que existen una diversidad de plantas, iii) suelos sin cobertura vegetal -o muy escasa- que resultan de la actividad mecánica por remoción de la capa arable, laboreo y compactado, situados en las laderas de los cerros y pocos en las planicies.

Tabla 2 Diversidad de plantas en el agroecosistema según el tipo del uso de suelo

\begin{tabular}{|c|c|c|}
\hline \multirow{2}{*}{ Uso del suelo } & \multicolumn{2}{|c|}{ Especie de plantas } \\
\hline & Nombres comunes & Nombres científicos \\
\hline \multirow[t]{12}{*}{ Natural (puruma) } & Ch'illiwa & Festuca sp. \\
\hline & Thola & $\begin{array}{l}\text { Parastrephia sp. } \\
\text { Deyeuxia sp. }\end{array}$ \\
\hline & Thola & $\begin{array}{l}\text { Baccharis sp. } \\
\text { Opuntia sp. } \\
\text { Adesmia sp. }\end{array}$ \\
\hline & K'oa & $\begin{array}{l}\text { Clinopodium sp. } \\
\text { Agrostis sp. }\end{array}$ \\
\hline & Cola de ratón & Herodium $\mathrm{sp}$ \\
\hline & cebadilla & Bromus sp. \\
\hline & Iru & $\begin{array}{l}\text { Stipa sp. } \\
\text { Dischitia sp. }\end{array}$ \\
\hline & Ch'iji & Trifolium sp. \\
\hline & & Muhlenbergia sp. \\
\hline & Diente de león & Taraxacum sp. \\
\hline & Muni muni & Bidens sp. \\
\hline & & $\begin{array}{l}\text { Distichlis sp. } \\
\text { Carex sp. }\end{array}$ \\
\hline \multirow[t]{4}{*}{ Con cultivo } & Cebada. & Hordeum vulgare. \\
\hline & Papa. & Solanum sp. \\
\hline & Quinua. & Chenopodium sp. \\
\hline & Cañahua. & Chenopodium sp. \\
\hline En descanso & & $\begin{array}{l}\text { Festuca sp. } \\
\text { Hordeum sp. } \\
\text { Poa sp. }\end{array}$ \\
\hline Sin cobertura & & $\begin{array}{l}\text { Festuca sp. } \\
\text { Poa sp. }\end{array}$ \\
\hline
\end{tabular}

Propiedades físicas, químicas y biológicas. De acuerdo al análisis de suelos (Tabla 1), estos presentan variadas características según el tipo de uso de suelo, vegetación nativa y cultivo. Destacan texturas del tipo franco arcillo arenosas. $\mathrm{El} \mathrm{pH}$ del suelo también varía de un lugar a otro, desde el mínimo de 6.65 (Vegetación nativa; Herodium sp.) hasta un máximo de 7.89 (cultivo quinua) y se encuentran en el rango de neutro a ligeramente alcalino. Por otro lado la conductividad eléctrica varía desde 0.03 (Distichlis sp., Trifolium sp.,) a 0.21 (cultivo quinua) $\mathrm{dS} \mathrm{m}^{-1}$.
La distribución de la MO va modificándose de acuerdo al uso del suelo, los valores máximos se encuentran en las zonas de vegetación natural o no perturbadas (suelo natural y vegetaciones nativas), las mínimas donde se realizan agricultura (suelos con cultivo y en descanso) y sin cobertura vegetal.

Diversidad de plantas. La mayor diversidad de plantas se presenta en el tipo de uso del suelo natural sin intervención o perturbación. Algunas especies nativas se agrupan en sitios vegetales determinados y distribuidos dentro de los suelos naturales. Los suelos en descanso presentan pocas especies mayormente plantas anuales. Por otro lado existen 
en el tipo de uso de suelo con cultivos, cultivos agrícolas como: Solanum sp., Hordeum sp., y Chenopodium sp. (Tabla 2 ).

Figura 1 Efecto del tipo de uso de suelo sobre el número de UFC's y especies de hongos filamentosos

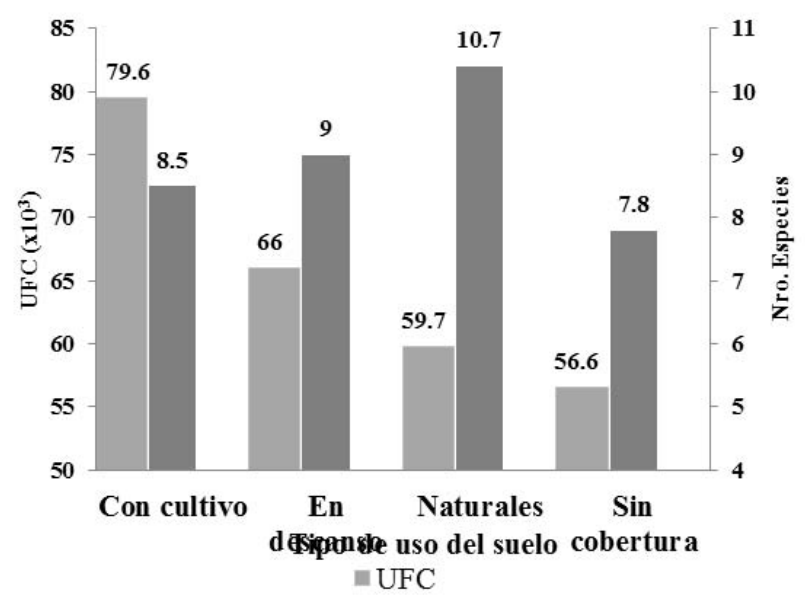

Efecto del uso del suelo, vegetación y cultivo sobre hongos filamentosos

Efecto del tipo de uso del suelo. La comparación de medias Duncan al $5 \%$ de significancia para la variable de respuesta UFC's, por el efecto del tipo de uso del suelo (Figura 1) muestran diferencias estadísticas entre tratamientos, en primer lugar las UFC's forman tres grupos, el cual los Suelos con Cultivos presentan mayor UFC's con $7.96 \times 10^{4} \mathrm{y}$ forma el primer grupo. El segundo grupo forma los Suelos en Descanso y Suelos Naturales que son similares estadísticamente con $6.6 \times 10^{4}$ y $5.97 \times 10^{4}$ UFC's. El Suelo sin cobertura presenta menor cantidad de UFC con $5.66 \times 10^{4}$.

Efecto del tipo de vegetación nativa. La figura 2, muestra la prueba Duncan en el cual no existen diferencias estadísticas para UFC's, pero si existen diferencias numéricas. En cambio si presenta diferencias en el número de especies de hongos filamentosos y forma dos grupos, el tratamiento Vegetación Nativa Trifolium sp., tiene mayor especies de hon- gos y forma el primer grupo con 10.4 y el segundo grupo los tratamientos de Vegetaciones Nativas de Festuca sp., con 9, Herodium sp., y Distichlis sp., ambos con 8.5.

Figura 2 Efecto del tipo de vegetación nativa sobre el número de UFC's y especies de hongos filamentosos

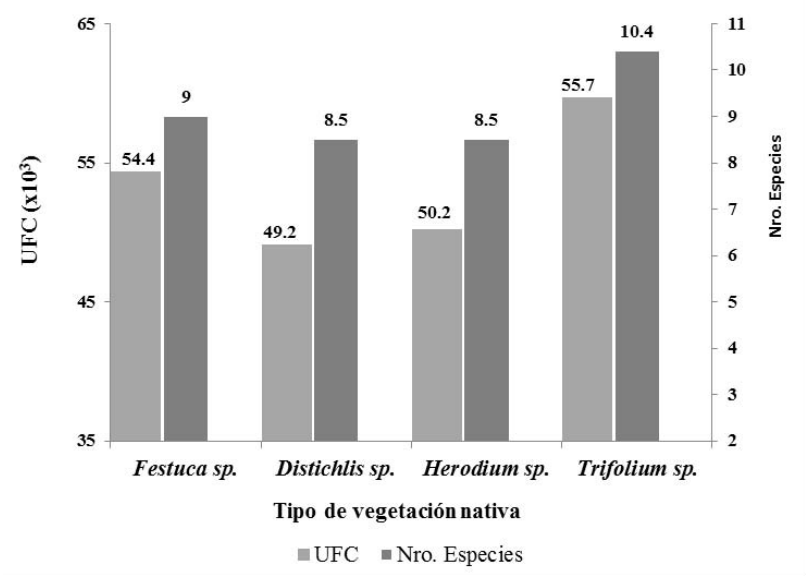

Figura 3 Efecto del tipo de cultivo sobre el número de UFC's y especies de hongos filamentosos

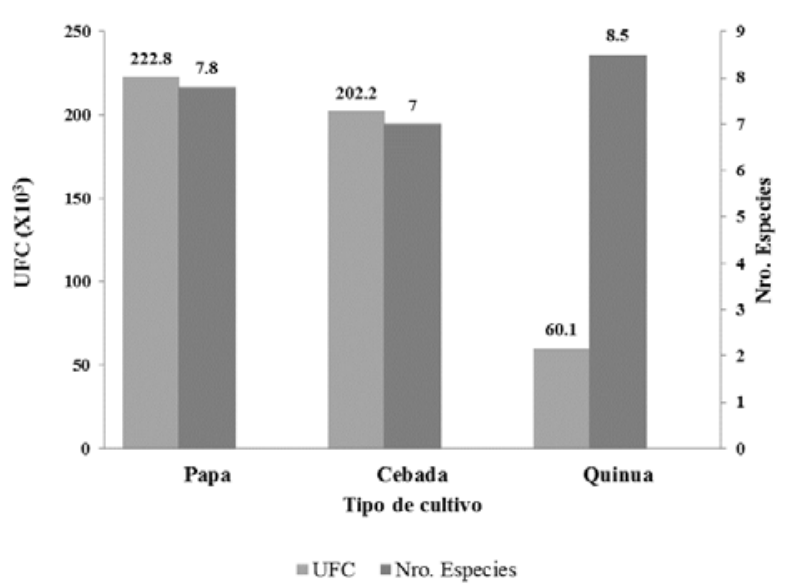

Efecto del tipo de cultivo. Según la figura 3 se observa los valores numéricos y la prueba de medias Duncan del efecto del tipo de cultivo sobre las UFC's y el número de especies. Las UFC's de hongos muestran que los suelos con cultivos de papa y cebada son similares estadísticamente con prome- 
dios de $22.2 \times 10^{4}$ y $20.2 \times 10^{4}$, así mismo son diferentes a los suelos con cultivo de quinua con $6.01 \times 10^{4}$. Para el número de especies el suelos con cultivo de quinua y papa presentan similitudes con promedios de 8.5 y 7.8 especies, los suelos con cultivo de cebada presento un promedio bajo con 7 especies.

Figura 4 Desarrollo macroscópico de las colonias de hongos filamentosos (anverso)

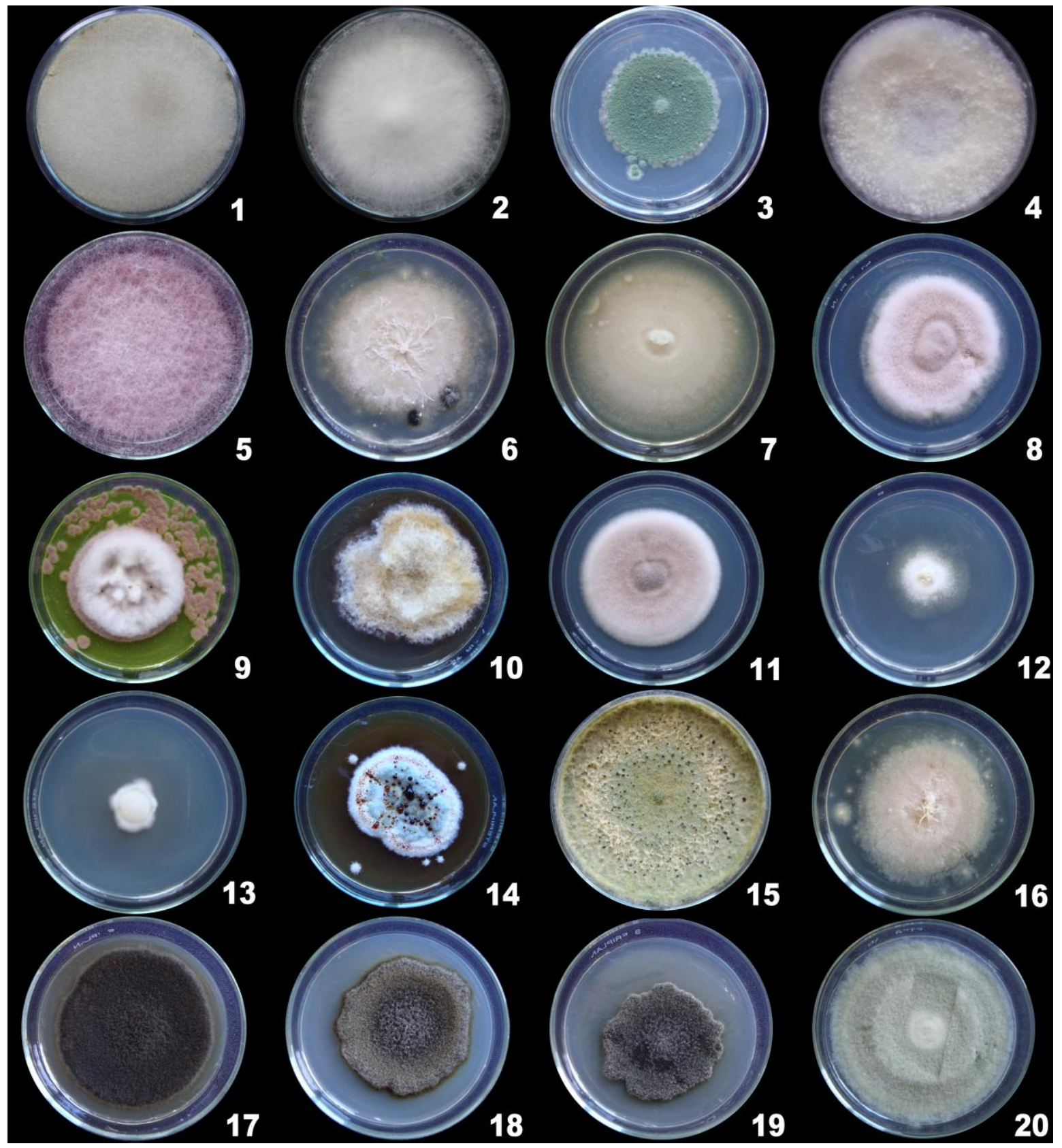


Figura 4 Desarrollo macroscópico de las colonias de hongos filamentosos (anverso) (Continuación)
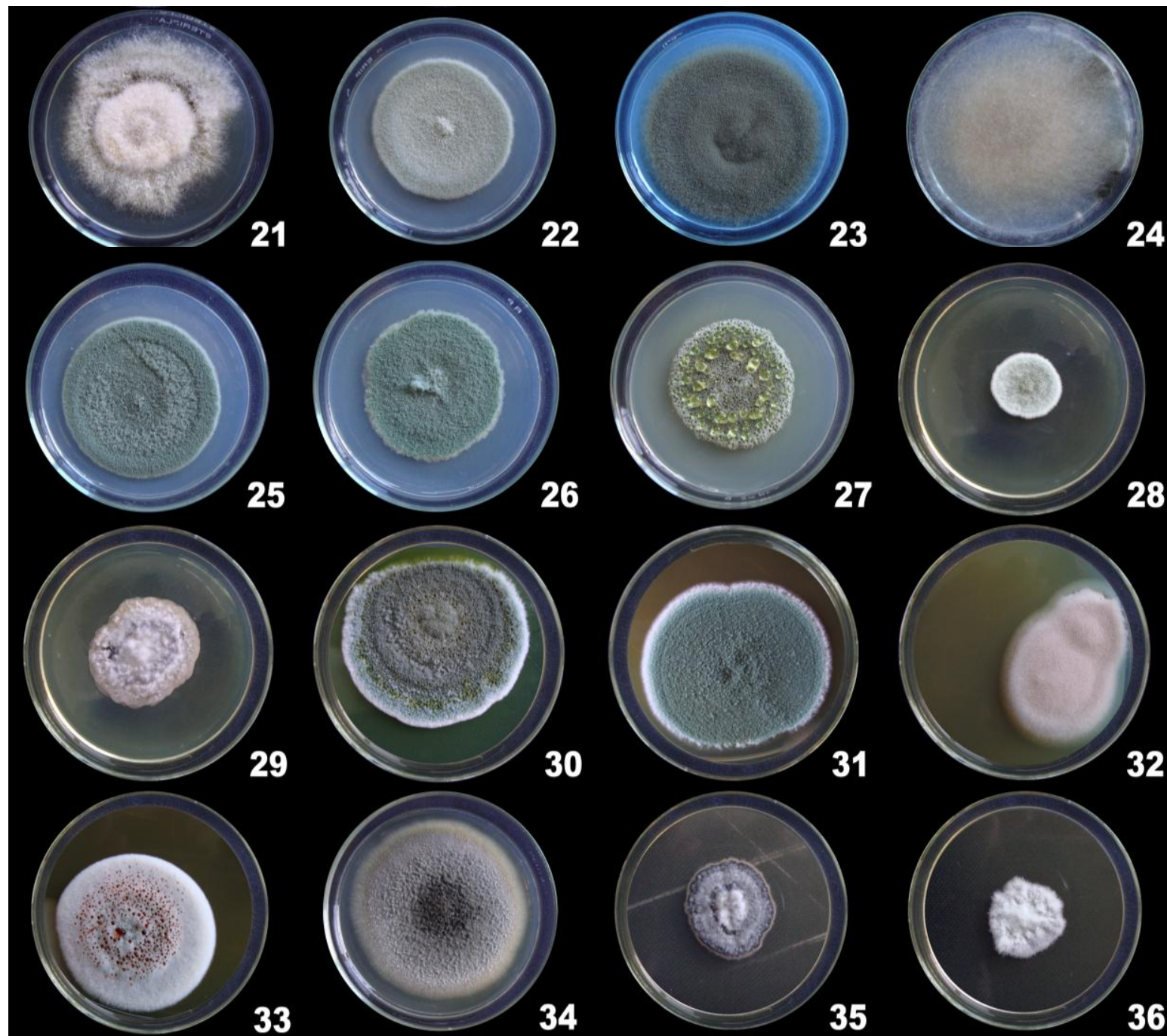

32
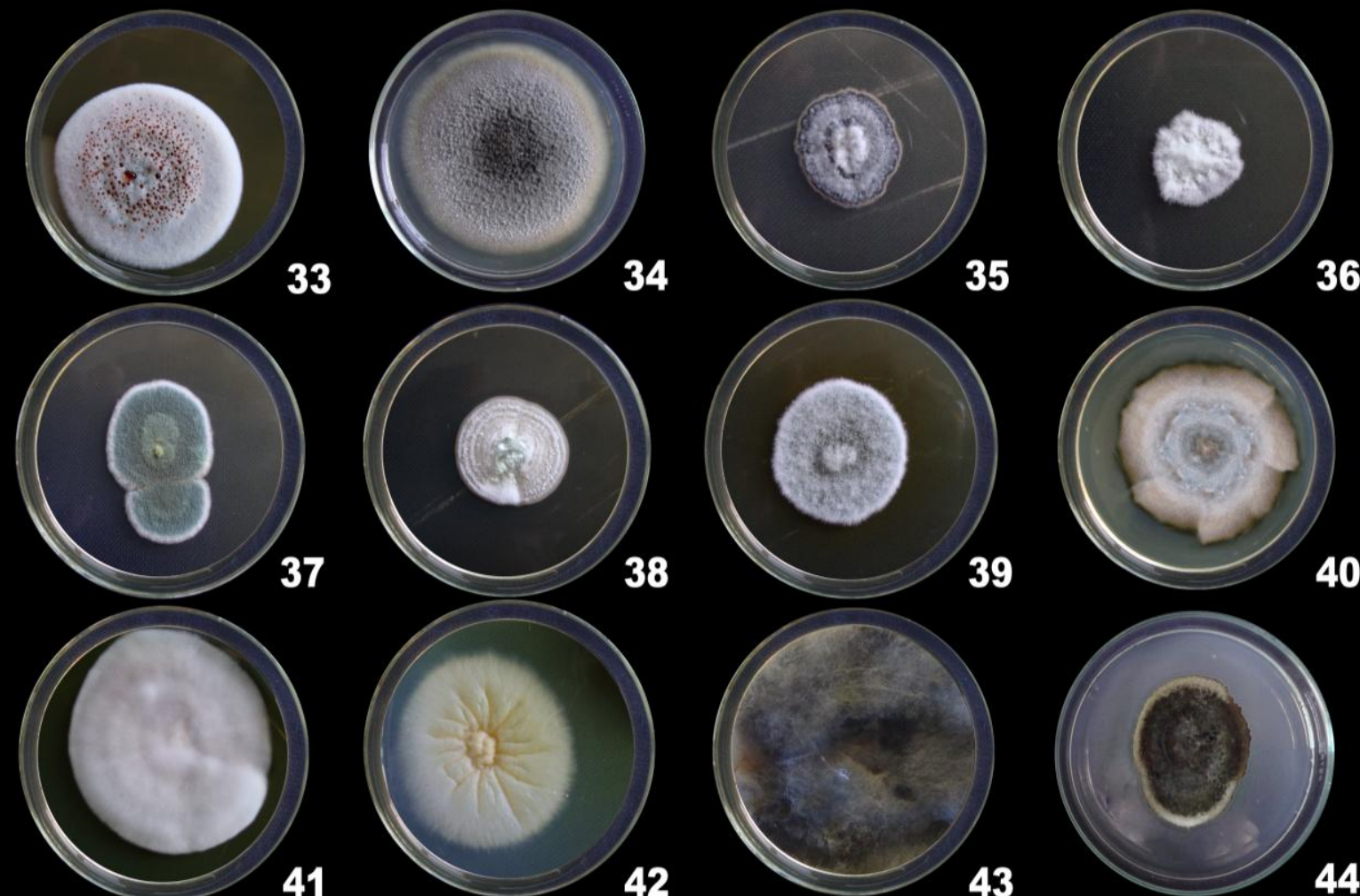

40

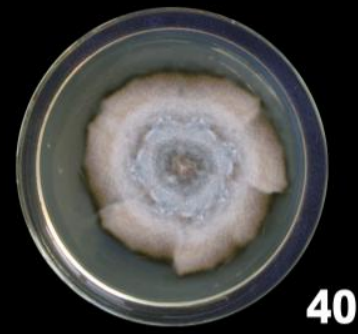

43

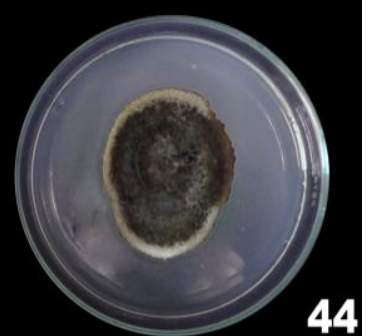


Figura 5 Desarrollo macroscópicas de las colonias de hongos filamentosos (reverso)

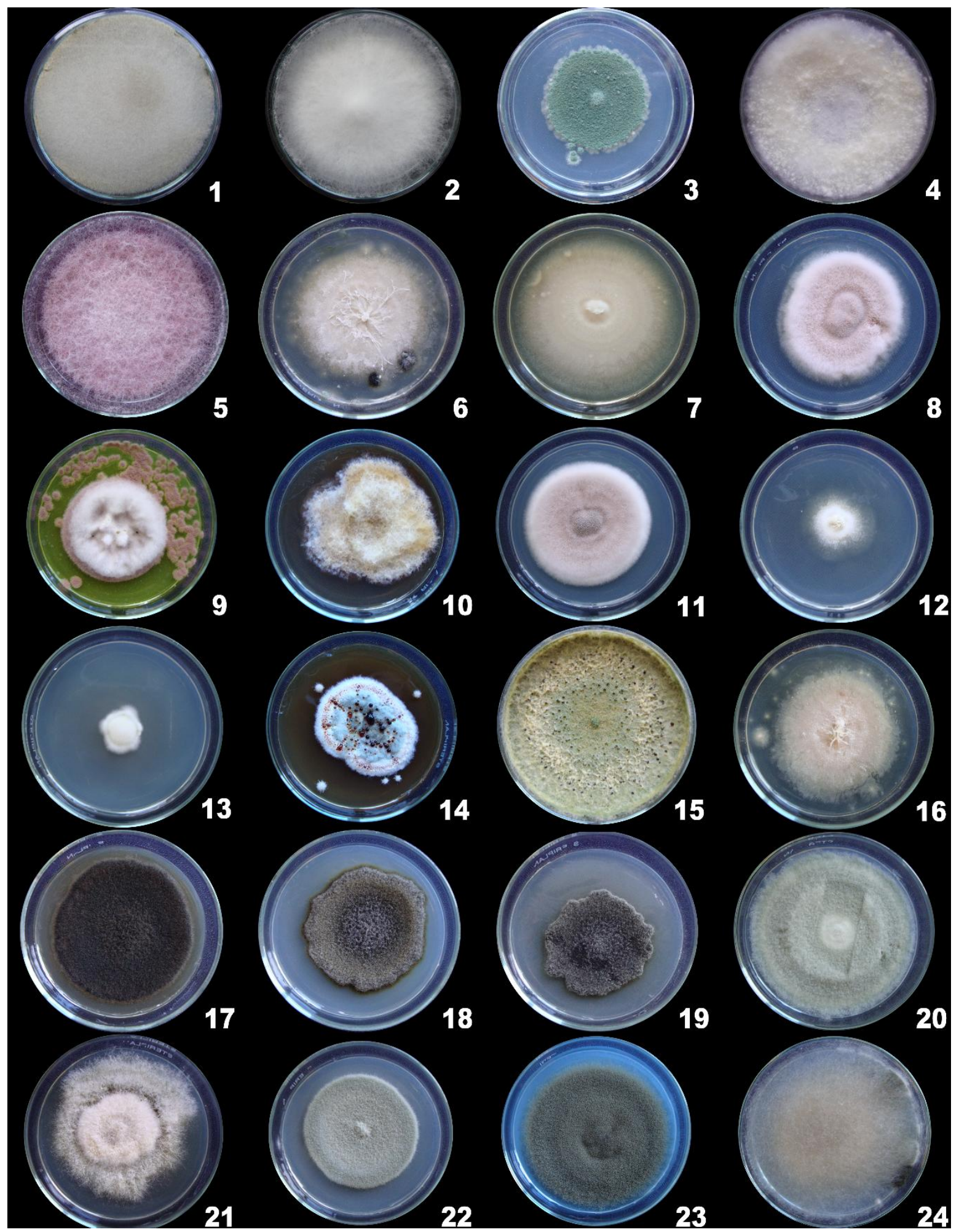


Figura 5 Desarrollo macroscópicas de las colonias de hongos filamentosos (reverso) (Continuación)
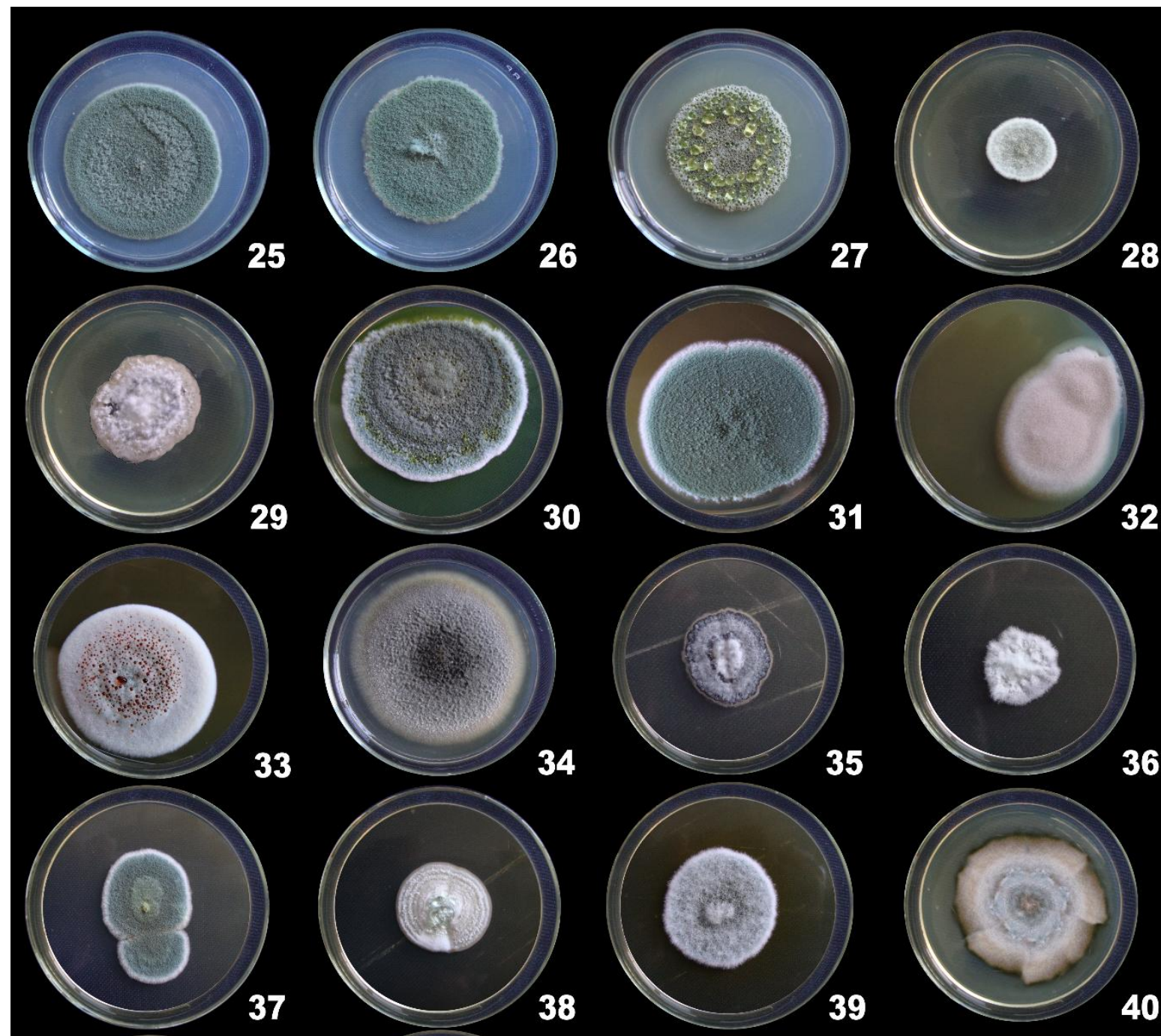

35
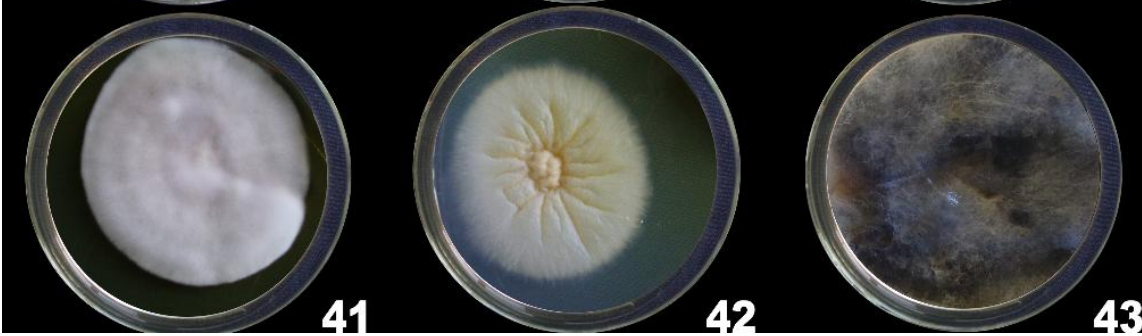

40
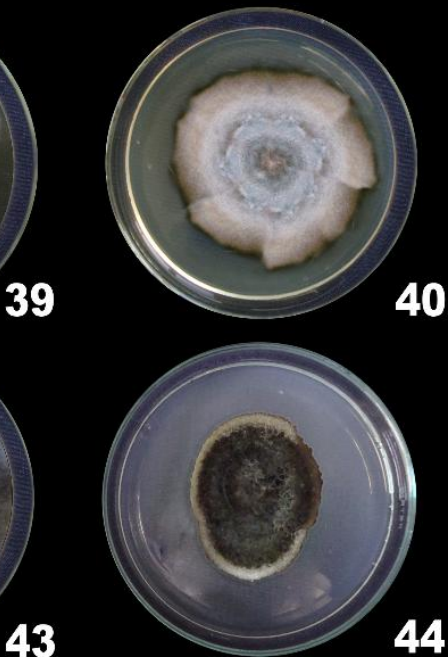
Figura 6 Observaciones microscópicas a 40X de las colonias de hongos filamentosos

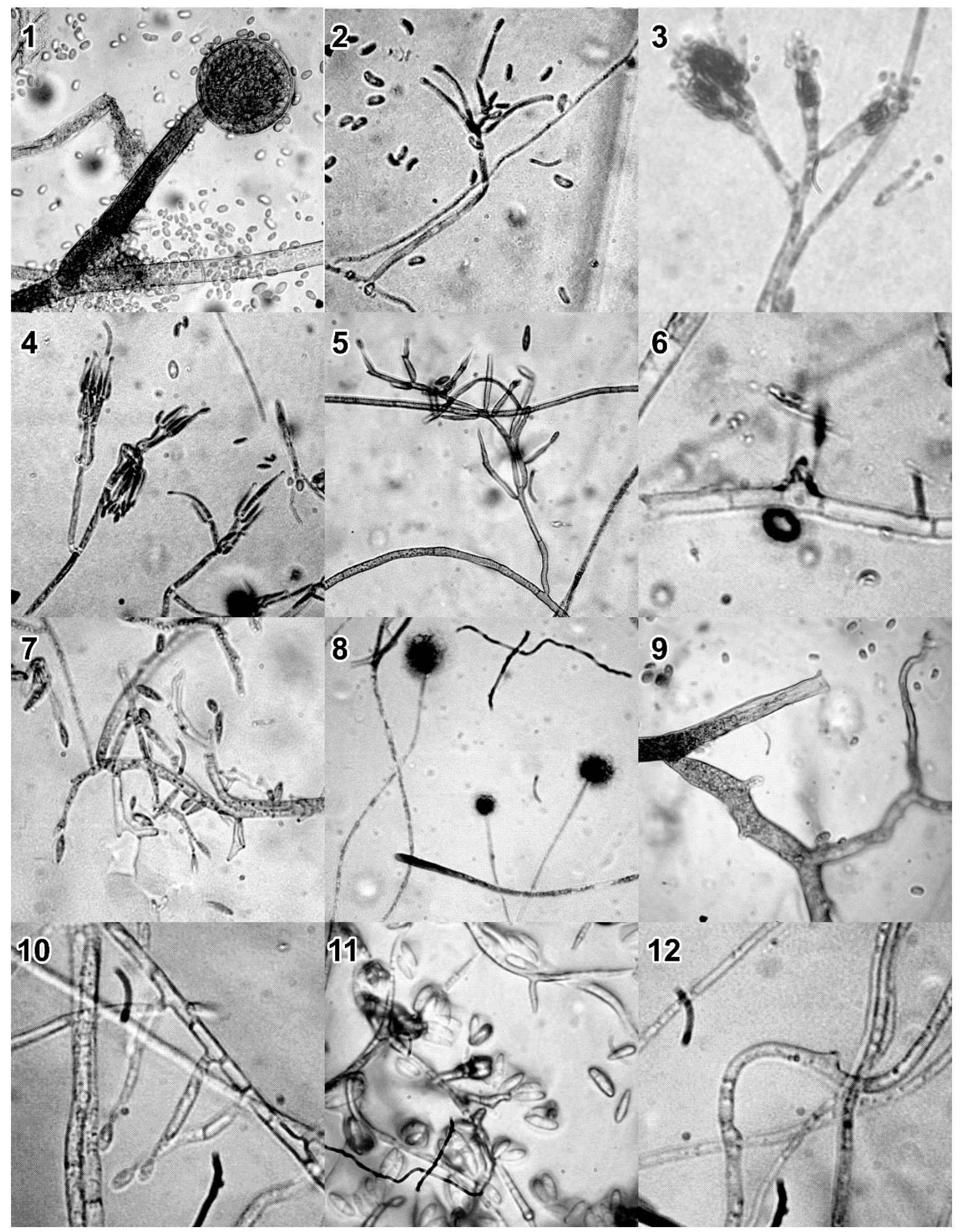


Figura 6 Observaciones microscópicas a 40X de las colonias de hongos filamentosos (Continuación)

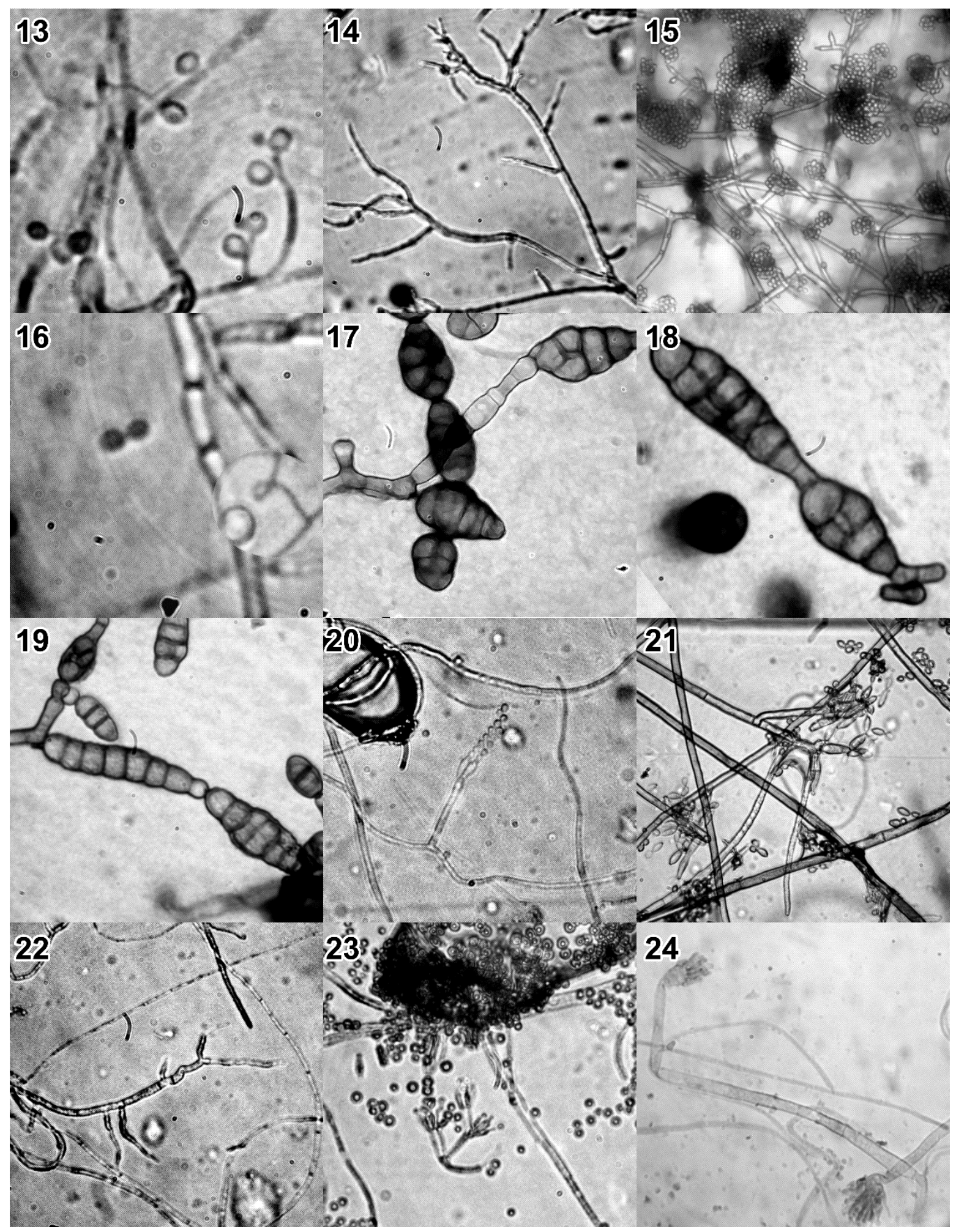


Figura 6 Observaciones microscópicas a 40X de las colonias de hongos filamentosos (Continuación)

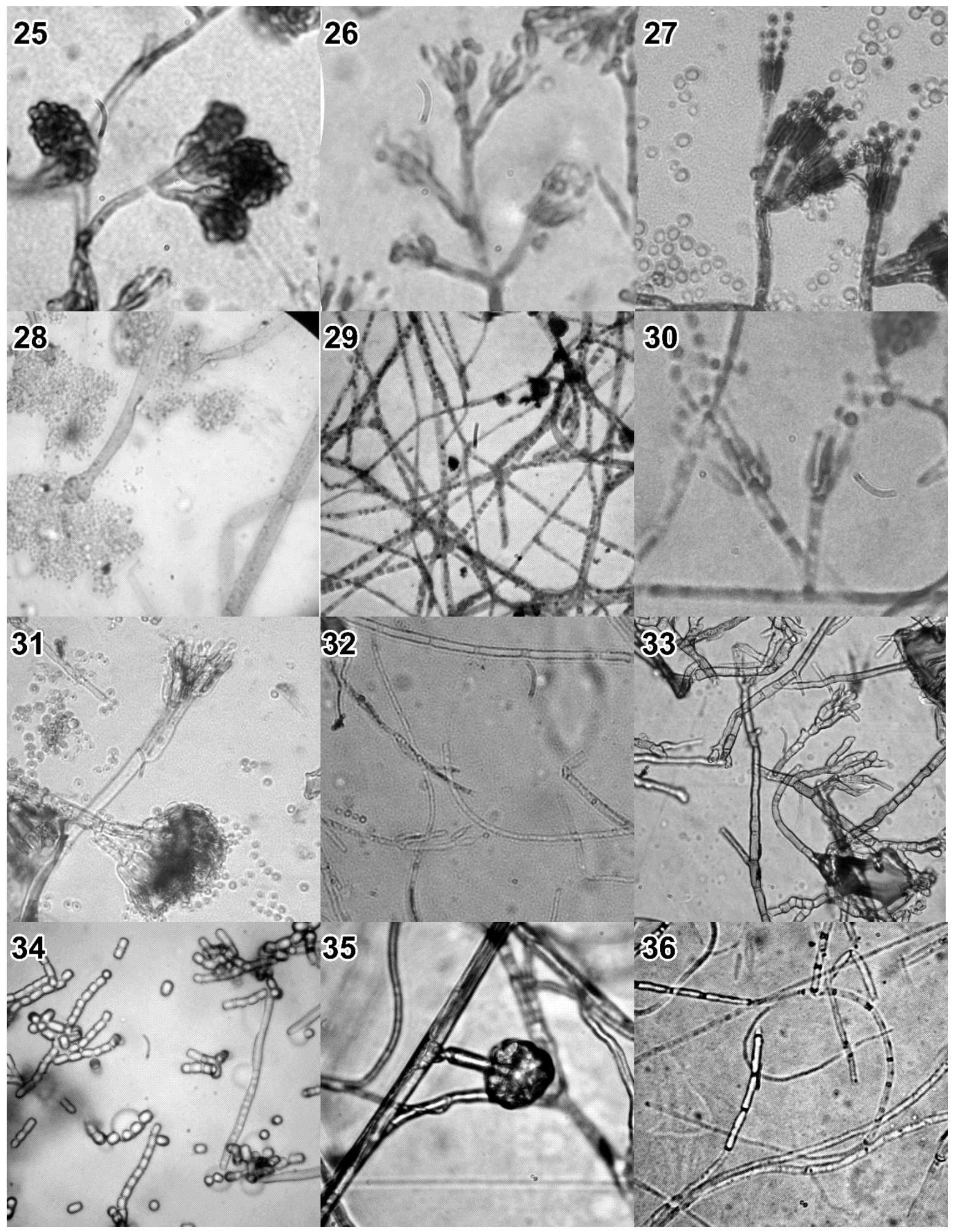


Figura 6 Observaciones microscópicas a 40X de las colonias de hongos filamentosos (Continuación)

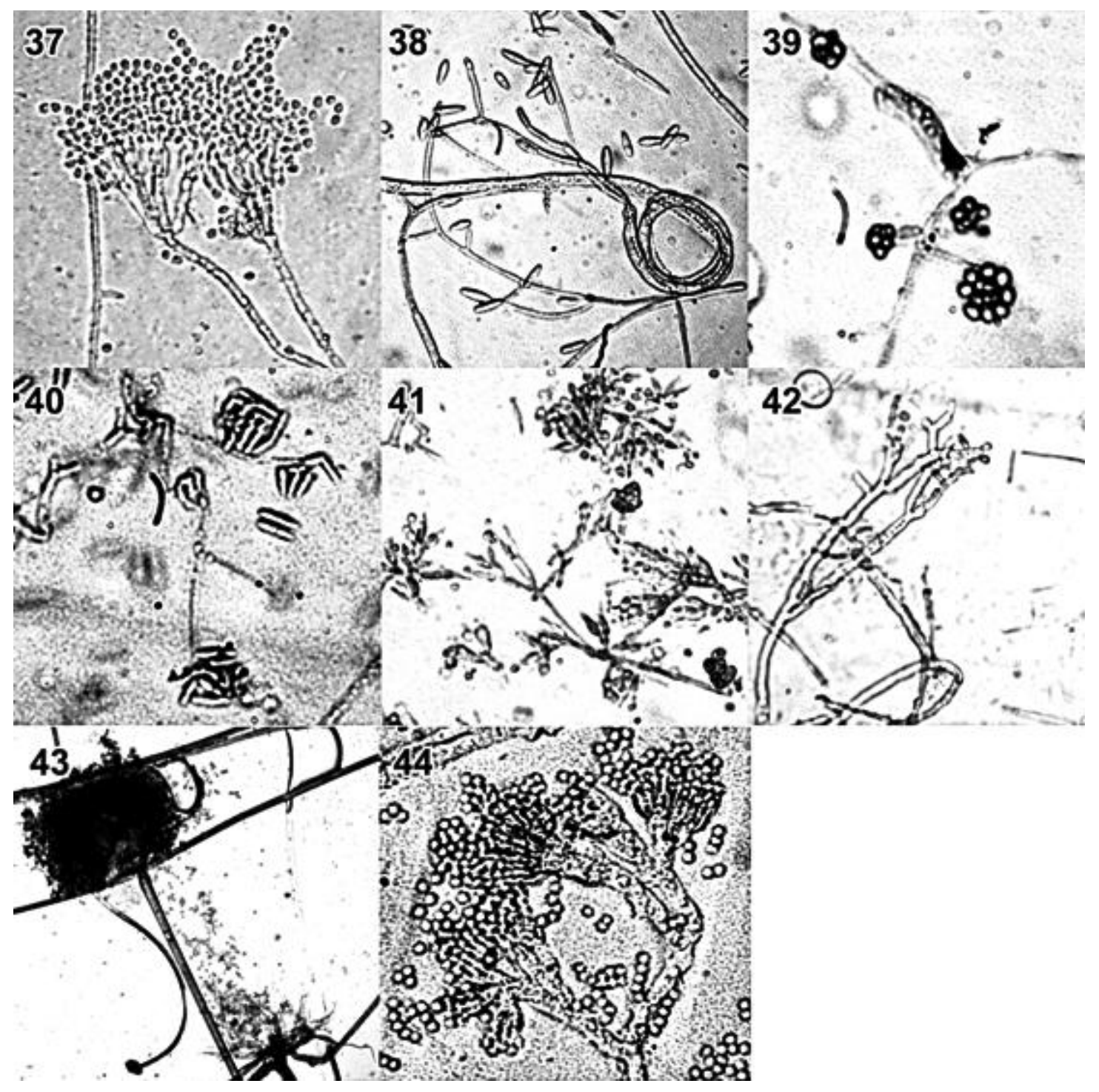

Descripción de especies de hongos filamentosos. De un total de 40 muestras compuestas de suelos, en primera instancia, por los diferentes medios de cultivos empleados se logró aislar aparentemente 110 especies de un inicial de 135 en cultivos puros en medio PDA. Las hongos prosperan principalmente por el medio usado (Bills et al. 2004), al parecer cuando se trasladaron las colonias al medio PDA, este no suministró ciertos nutrientes para el desarro- llo de hongos, por lo tanto 25 especies se perdieron definitivamente.

Las 110 especies de hongos filamentosos se desarrollaron en el medio PDA, pero al transcurrir el tiempo fueron retiradas 42 especies entre los tratamientos, a aquellos hongos con características iguales en el anverso y reverso de las colonias. La similitud podría ser debido a los medios de cultivos PDA, HLP, SA, HMA y AES, ya que estos propor- 
cionaron diferentes cantidades y tipos nutrientes (Vieira \& Nahas 2005).

68 especies de hongos sumaron entre los tres factores de estudio, del cual 24 fueron similares entre los tratamientos, quedando al final 44 hongos filamentos en suelos del agroecosistema, cada uno diferente a los demás.

Las figuras 4 y 5 muestran imágenes macroscópicas del anverso y reverso de las colonias de hongos filamentosos en caja Petri tomadas al séptimo día. La tabla 3 muestra las descripciones de las carac- terísticas macroscópicas (anverso y reverso) que presentaron las colonias de hongos filamentosos en medio de cultivo PDA. La figura 6 muestra las imágenes obtenidas a través del microscopio de sus características microscópicas de sus estructuras reproductivas de cada uno en microcultivos.

Identificación de hongos filamentosos. La tabla 4 muestra la lista de hongos filamentosos encontrados por el tipo de uso de suelo, tipo de cultivo y tipo de vegetación nativa.

Tabla 3 Descripción microscópica del anverso y reverso de los hongos filamentosos

\begin{tabular}{|c|c|}
\hline Cepa & Características macroscópicas (anverso y reverso) \\
\hline 1 & $\begin{array}{l}\text { Colonia circular elevada de color gris pálido, de rápido crecimiento y textura algodonosa densa. Reverso color } \\
\text { blanco crema con bordes filamentosos. }\end{array}$ \\
\hline 2 & $\begin{array}{l}\text { Colonia circular de color blanco, textura algodonosa aterciopelada, superficie elevada en el centro y disminuye hacia } \\
\text { los bordes. Reverso color blanco crema intensa con borde filamentoso. }\end{array}$ \\
\hline 3 & $\begin{array}{l}\text { Colonia circular irregular con anillos de color verde blanquecino (centro), verde claro (interior) y borde irregular de } \\
\text { color blanco crema, textura polvorienta. Reverso con anillos color blanco crema (interior), blanco amarillento (me- } \\
\text { dio) y borde irregular nuboso. }\end{array}$ \\
\hline 4 & $\begin{array}{l}\text { Colonia circular aterciopelada de color blanco y textura granular. Reverso color blanco crema con filamentos en todo } \\
\text { su interior. }\end{array}$ \\
\hline 5 & $\begin{array}{l}\text { Colonia circular de rápido crecimiento, textura densa aérea plumosa, pigmentación de color rojo intenso. Reverso } \\
\text { rojo intenso. }\end{array}$ \\
\hline 6 & $\begin{array}{l}\text { Colonia irregular plana de color crema con formación de rizoides aéreos y borde filamentoso. Reverso centro color } \\
\text { blanco crema con estrías. }\end{array}$ \\
\hline 7 & $\begin{array}{l}\text { Colonia circular de color crema con formación de anillos circulares y bordes filamentosos, de textura plana con estría } \\
\text { circular en su centro. Reverso amarillo blanquecino con estría en el centro. }\end{array}$ \\
\hline 8 & $\begin{array}{l}\text { Colonia de forma ovalada con formación de anillos de color rosa a blanca en los bordes, textura lanosa y estría en el } \\
\text { centro. Reverso con anillos café en el centro y blanco en su borde. }\end{array}$ \\
\hline 9 & $\begin{array}{l}\text { Colonia circular de color blanco y rojo crema en los bordes, textura lanosa elevada. Reverso amarillo intenso y con } \\
\text { estrías en forma de estrella. }\end{array}$ \\
\hline 10 & Colonia irregular algodonosa de color combinado de café claro y blanco. Reverso café intenso. \\
\hline 11 & $\begin{array}{l}\text { Colonia circular elevada en el centro de color rosa bajo a blanco hacia los bordes y textura lanosa. Reverso café claro } \\
\text { en su centro y borde blanco. }\end{array}$ \\
\hline 12 & $\begin{array}{l}\text { Colonia circular de color blanco crema con borde filamentoso, textura algodonosa y elevada en su centro. Reverso } \\
\text { blanco crema y estría circular en su centro. }\end{array}$ \\
\hline 13 & Colonia circular de color blanco con borde irregular ondulado y textura algodonosa. Reverso amarillo blanquecino. \\
\hline 14 & $\begin{array}{l}\text { Colonia circular con anillos de color celeste, rojo y blanco, textura lanosa elevada, formación de exudados de color } \\
\text { rojo purpura. Reverso café oscuro con borde café claro y con estrías. }\end{array}$ \\
\hline 15 & $\begin{array}{l}\text { Colonia de forma circular aplanada de color verde amarillento, textura aterciopelada con formación de exudados de } \\
\text { color café oscuro. Reverso amarillo pálido. }\end{array}$ \\
\hline 16 & $\begin{array}{l}\text { Colonia circular de color rosa brema y con bordes filamentosos color blanco crema, textura rizoide. Reverso blanco } \\
\text { crema amarillento. }\end{array}$ \\
\hline 17 & $\begin{array}{l}\text { Colonia circular de color café oscuro y borde plomo, textura lanosa. Reverso con anillos café oscuro, café, café } \\
\text { oscuro y café claro, con estrías en todo su interior. }\end{array}$ \\
\hline 18 & $\begin{array}{l}\text { Colonia circular irregular de color café plomizo (centro), anillos café claro y plomo claro y borde café oscuro, textu- } \\
\text { ra lanosa elevada. Reverso café negruzco. }\end{array}$ \\
\hline 19 & Colonia de forma irregular de color plomo oscuro, textura lanosa elevada. Reverso café negruzco. \\
\hline 20 & $\begin{array}{l}\text { Colonia circular con anillos de color verde claro y verde limón, borde filamentoso y de textura algodonosa. Reverso } \\
\text { blanco crema. }\end{array}$ \\
\hline 21 & $\begin{array}{l}\text { Colonia circular de color café blanquecino con borde irregular filamentoso, textura algodonosa. Reverso con anillos } \\
\text { irregulares verde, café oscuro y café claro. }\end{array}$ \\
\hline
\end{tabular}


Tabla 3 Descripción microscópica del anverso y reverso de los hongos filamentosos (Continuación)

\begin{tabular}{|c|c|}
\hline Cepa & Características macroscópicas (anverso y reverso) \\
\hline 22 & $\begin{array}{l}\text { Colonia circular verde blanquecina con borde blanco, textura lanosa elevada en su interior. Reverso blanco crema } \\
\text { con anillos. }\end{array}$ \\
\hline 23 & $\begin{array}{l}\text { Colonia circular de color verde café con borde filamentoso y textura lanosa. Reverso verde negruzco y con estrías en } \\
\text { su centro. }\end{array}$ \\
\hline 24 & Colonia circular globosa irregular de color café claro, textura algodonosa. Reverso blanco crema. \\
\hline 25 & $\begin{array}{l}\text { Colonia circular de color verde y borde blanco, con formación de anillos elevados y textura polvorienta. Reverso } \\
\text { blanco crema verdusco y con anillos. }\end{array}$ \\
\hline 26 & $\begin{array}{l}\text { Colonia circular irregular de color verde y borde blanco, textura polvorienta. Reverso amarillo intenso y bordes } \\
\text { blancos. }\end{array}$ \\
\hline 27 & $\begin{array}{l}\text { Colonia de color verde y borde blanco, circular y textura polvorienta con formación de exudados de color verde } \\
\text { claro. Reverso blanco cremoso y con estría en su centro. }\end{array}$ \\
\hline 28 & $\begin{array}{l}\text { Colonia circular irregular de color blanca plomiza y borde filamentoso color blanco, textura algodonosa. Reverso } \\
\text { café blanquecino y borde blanco cremoso. }\end{array}$ \\
\hline 29 & $\begin{array}{l}\text { Colonia irregular de color blanco crema, textura algodonosa y con borde cremoso. Reverso con anillos irregulares } \\
\text { blanco, plomo y plomo blanquecino con estría en su centro. }\end{array}$ \\
\hline 30 & $\begin{array}{l}\text { Colonia circular con anillos verde, verde oscuro, verde claro y borde blanco, textura polvorienta con exudados de } \\
\text { color verde claro. Reverso amarillo intenso y degradándose a blanco hacia sus bordes, en su centro estría circular } \\
\text { encerrando a otra en forma de estrella. }\end{array}$ \\
\hline 31 & Colonia circular de color verde y borde blanco, textura polvorienta. Reverso café claro amarillento. \\
\hline 32 & $\begin{array}{l}\text { Colonia irregular de color rosa pálido y borde blanco, textura lanosa algodonosa. Reverso con anillos irregulares café } \\
\text { oscuro, café blanquecino, café claro y blanco crema su borde. }\end{array}$ \\
\hline 33 & $\begin{array}{l}\text { Colonia circular blanco, textura lanosa con formación de exudados de color rojo oscuro. Reverso café y degradándo- } \\
\text { se a café amarillento hacia su borde. }\end{array}$ \\
\hline 34 & $\begin{array}{l}\text { Colonia circular con anillos de color plomo oscuro, plomo, plomo blanquecino, café y borde filamentoso café claro, } \\
\text { textura polvorienta. Reverso con anillos filamentosos negro degradándose a café y borde blanco. }\end{array}$ \\
\hline 35 & $\begin{array}{l}\text { Colonia irregular con anillos de color blanco, plomo, blanco, plomo con blanco y borde café crema, textura lanosa } \\
\text { algodonosa. Reverso con anillos irregulares blanco, plomo y borde blanco crema y estrías en su centro. }\end{array}$ \\
\hline 36 & $\begin{array}{l}\text { Colonia irregular de color gris blanquecino, borde filamentoso y textura algodonosa. Reverso color negro en su } \\
\text { centro con estrías y borde blanco. }\end{array}$ \\
\hline 37 & $\begin{array}{l}\text { Colonia oval con anillos de color verde limón, verde claro, verde y borde blanco, textura polvorienta algodonosa. } \\
\text { Reverso amarillo degradándose a blanco hacia sus bordes. }\end{array}$ \\
\hline 38 & $\begin{array}{l}\text { Colonia circular de color blanco y cremoso con anillos, textura lanosa algodonosa. Reverso blanco amarillento } \\
\text { crema. }\end{array}$ \\
\hline 39 & $\begin{array}{l}\text { Colonia circular combinado de verde y blanco, borde filamentoso y textura algodonosa. Reverso con anillos irregula- } \\
\text { res blanco naranja, naranja y borde blanco amarillento. }\end{array}$ \\
\hline 40 & olonia irregular con anillos, textura algodonosa lanosa. Reverso con anillos de color rojo vino. \\
\hline 41 & lonia circular de color blanco y textura lanosa. Reverso blanco amarillento y con estrías en su centro. \\
\hline 42 & $\begin{array}{l}\text { Colonia circular color amarillo cremoso con estrías que aparentan una estrella y borde filamentoso, textura cremosa } \\
\text { filamentosa. Reverso blanco cremoso y con formación de estrías en su centro. }\end{array}$ \\
\hline 43 & Colonia circular de rápido crecimiento de color café oscuro y blanco, textura algodonosa. Reverso café negruzco. \\
\hline 44 & $\begin{array}{l}\text { Colonia oval verde oscuro y borde blanco, textura polvorienta. Reverso con anillos de color blanco crema, amarillo } \\
\text { naranja y borde blanco crema. }\end{array}$ \\
\hline
\end{tabular}

El total de hongos filamentosos obtenidos fue de 44 especies en cultivos puros, los cuales fueron comparados con descripciones originales de acuerdo a sus características morfológicas vistas al microscopio, para hongos en general: Barnett \& Hunter 1998, Kirk et al. 2008, Watanabe 2010, Samson, et al. 2014, para géneros de Aspergillus y Penicillium. Aquellos hongos filamentosos no identificados fueron denominados como cepas no tipificadas.
Las siguientes divisiones identificadas por microscopia fueron: Zigomycota y Basidiomycota cada uno con dos especies y Ascomycota con 40 especies. 15 hongos filamentosos fueron debidamente identificados a nivel de género. Los 29 restantes no fue posible su identificación y se denominaron como cepas no tipificadas, sin embargo de acuerdo a sus características microscópicas fueron asignados a una probable división. 
Tabla 4 Especies de hongos filamentosos aislados en relación con el lugar de muestreo

\begin{tabular}{|c|c|c|c|}
\hline No. de especie & División & Hongo filamentoso & Lugar de muestreo \\
\hline 1 & Zigomycota & Absidia sp. & TUS, TC y TVN. \\
\hline 43 & & Rhizopus sp. & TUS, TC y TVN. \\
\hline 6 & Basidiomycota & Cepa 6 & $\mathrm{TC} 1$. \\
\hline 16 & & Cepa 16 & TC1. \\
\hline 3 & Ascomycota & Penicillium sp. & TUS4. \\
\hline 5 & & Fusarium sp. & TVN2 y TUS2. \\
\hline 15 & & Trichoderma sp. & TC3, TVN1, TUS2 y TUS4 \\
\hline 17 & & Alternaria sp. & $\mathrm{TC} 2$. \\
\hline 18 & & Alternaria sp. & TVN1. \\
\hline 19 & & Alternaria sp. & TVN2. \\
\hline 25 & & Penicillium sp. & TVN4. \\
\hline 26 & & Penicillium sp. & TC1 y TVN3. \\
\hline 27 & & Penicillium sp. & TVN4. \\
\hline 30 & & Penicillium sp. & TUS4 y TVN3. \\
\hline 31 & & Penicillium sp. & TC1 y TVN4. \\
\hline 37 & & Penicillium sp. & TVN3. \\
\hline 44 & & Penicillium sp. & TVN2. \\
\hline 4 & & Cepa $4 *$ & TVN4 y TUS2. \\
\hline 10 & & Cepa $10^{*}$ & TC3 y TVN2. \\
\hline 2 & & Cepa $2 *$ & TC3, TUS2 y TUS4. \\
\hline 7 & & Cepa $7 *$ & TC2, TC3 y TVN3. \\
\hline 8 & & Cepa $8 *$ & TVN1. \\
\hline 9 & & Cepa $9^{*}$ & TVN4. \\
\hline 11 & & Cepa $11 *$ & $\mathrm{TC} 2$. \\
\hline 12 & & Cepa $12 *$ & TVN3. \\
\hline 13 & & Cepa $13^{*}$ & TC3, TVN4 y TUS2. \\
\hline 14 & & Cepa $14^{*}$ & TC2 y TVN1. \\
\hline 20 & & Cepa $20^{*}$ & $\mathrm{TC} 1$. \\
\hline 21 & & Cepa $21 *$ & TVN3. \\
\hline 22 & & Cepa $22 *$ & TVN1. \\
\hline 23 & & Cepa 23* & TUS4. \\
\hline 24 & & Cepa $24 *$ & TC3, TVN1 y TVN3. \\
\hline 28 & & Cepa 28* & TVN1. \\
\hline 29 & & Cepa 29* & TC2 y TVN2. \\
\hline 32 & & Cepa $32 *$ & TUS2. \\
\hline 33 & & Cepa $33 *$ & TVN1. \\
\hline 34 & & Cepa $34 *$ & TVN2. \\
\hline 35 & & Cepa $35^{*}$ & TC1, TC2 y TVN3. \\
\hline 36 & & Cepa $36^{*}$ & TC3 y TVN4. \\
\hline 38 & & Cepa $38^{*}$ & TUS2 y TUS4. \\
\hline 39 & & Cepa 39* & TVN4. \\
\hline 40 & & Cepa $40^{*}$ & TUS2 y TC3. \\
\hline 41 & & Cepa $41^{*}$ & TVN2. \\
\hline 42 & & Cepa $42 *$ & TVN2. \\
\hline
\end{tabular}

*Cepas de hongos no identificadas a nivel género pero si a nivel de división. 
Relaciones entre el \%MO, pH y textura con la abundancia de hongos. La interacción de las variables \%MO y UFC's (Figura 7), tuvo un coeficiente de correlación de Pearson de -0.56 , la cual indica que ambas variables tienen una relación lineal negativa, aunque esta no es estadísticamente significativa $\left(\mathrm{r}^{2}=32.1 \% ; \mathrm{p}>0.05\right)$ y siendo la ecuación de regresión UFC's = $65344-1730$ \% MO.

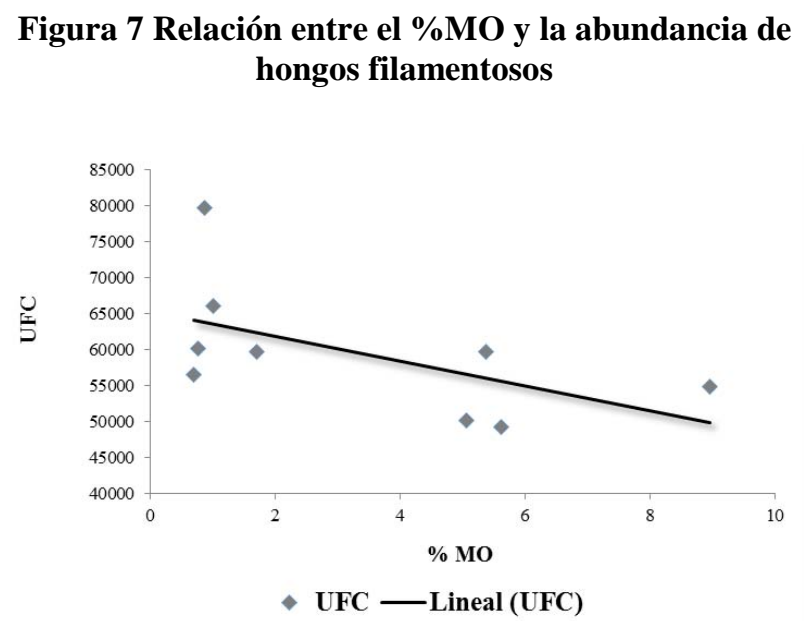

Figura 8 Relación entre el pH y la abundancia de hongos filamentosos

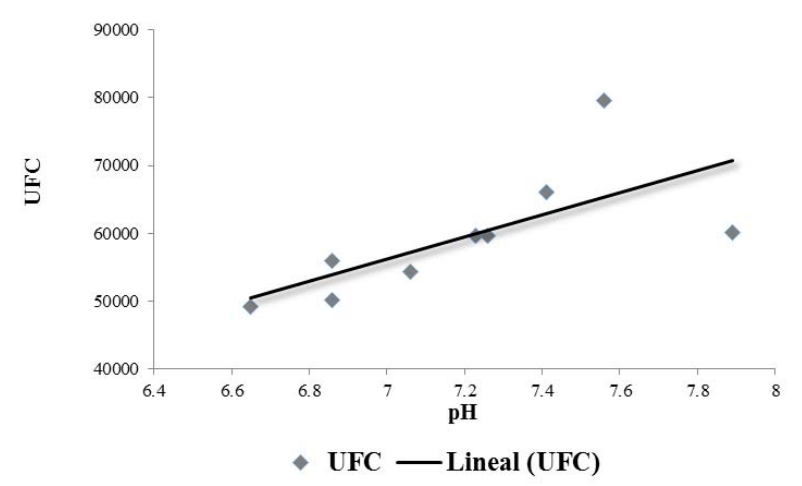

Mientras la interacción de variables $\mathrm{pH}$ y UFC's (Figura 8), demuestra que ambas variables tienen una relación positiva (coeficiente de correlación de Pearson 0.69). Esta relación indica que cuando el $\mathrm{pH}$ aumenta la UFC's tiende a aumentar (UFC's = $58364+16366 \mathrm{pH})$ y estadísticamente presenta significativa $\left(r^{2}=47.7 \% ; \mathrm{p}<0.05\right)$.
Finalmente las interacciones de las variables \%Arena y UFC's (Figura 9) tuvo un coeficiente de correlación de Pearson de 0.29, el cual indica que ambas variables no tienen relación $\left(\mathrm{UFC}^{\prime} \mathrm{s}=50560+\right.$ $143 \%$ Arena) y estadísticamente no es significativa $\left(r^{2}=8.6 \% ; p>0.05\right)$.

\section{Figura 9 Relación entre el \%Arena y la abundancia de hongos filamentosos}

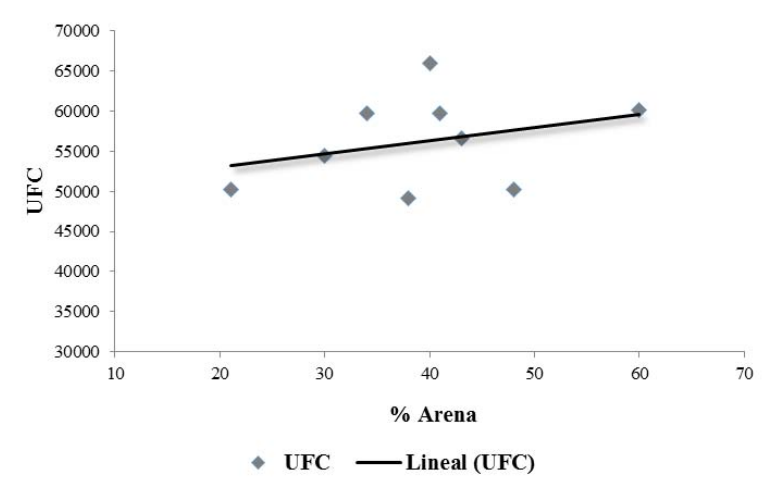

\section{Discusión}

El presente estudio, fue el primero en caracterizar la comunidad de hongos del suelo en un agroecosistema del altiplano central del Estado Plurinacional de Bolivia. Variables físicas, químicas y biológicas fueron medidas y relacionadas con UFC's y especies de hongos filamentosos del suelo.

Efectos del tipo de uso del suelo. $\mathrm{El} \mathrm{pH}, \% \mathrm{MO}$ y la TS dentro del agroecosistema difieren numéricamente por el tipo de uso del suelo. Lauber et al. (2008) menciona que a menudo el tipo de uso de suelo, acorde con las prácticas de manejo (fertilización y abonamiento) tienen efectos apreciables en las concentraciones de nutrientes y su textura. La agricultura afecta la cantidad de $\% \mathrm{MO}, \mathrm{pH}$ y agregación del suelo (Coyne 2000, Dixon \& Tilston 2010). 
La MO es alta en suelos de ecosistemas naturales, pero son bajos en un agroecosistema debido a que las entradas de materia orgánica son menores y las prácticas frecuentes, promueven la oxidación de la MO (Meliani et al. 2012). Principalmente el tipo de uso del suelo, causa diferentes efectos en las propiedades físicas, químicas y biológicas (Swift \& Bignell 2001). Los resultados evidencian estas diferencias en sus propiedades del suelo por el tipo de uso, vegetación nativa y prácticas de manejo de los cultivos agrícolas que incluyen fertilización química y control de plagas con pesticidas, la baja diversidad de especies podría deberse a estos factores.

Las UFC's fueron mayores en suelos con cultivos a comparación de los naturales donde se presentaron mayor diversidad. Este efecto podría atribuirse a la diversidad de plantas presentes en los suelos naturales, por las cantidades de materia orgánica y por los exudados de las plantas (azúcar, aminoácidos, proteínas, entre otros) que estimulan el crecimiento de los microorganismos (Broeckling et al. 2008). La agricultura y la diversidad de plantas afectan a la distribución y composición de hongos (Coyne 2000), la agricultura afecta drásticamente la diversidad de hongos por la perturbación constante del suelo y explicaría en este trabajo, la menor diversidad de hongos en suelos con cultivo. La producción agrícola altera su hábitat y por lo tanto daña a toda la comunidad microbiana, lo cual disminuye la diversidad y abundancia de estos hongos (Sivila \& Hervé 1999, Altieri 1999, Carlile et al. 2001, Cabello \& Arambarri 2002). En general las poblaciones microbianas son alteradas por la riqueza de especies de plantas, la diversidad de hongos aumenta con una alta diversidad de plantas (Zak et al. 2003).

Efecto del tipo de vegetación nativa. La vegetación nativa Trifolium sp., presento mayor UFC's y número de especies, coincidiendo con Sivila de Cary \& 21
Angulo (2006) que en parcelas con leguminosas nativas en el altiplano central del Estado Plurinacional de Bolivia encontraron mayor UFC's $\left(6.4 \times 10^{4}\right)$ en comparación con parcelas con gramíneas (5.6 $\mathrm{x} 10^{4}$ ). Esta particularidad podría deberse a la presencia de las leguminosas, que proveen ciertos nutrientes que favorecieron la diversidad y UFC's de hongos. Los exudados de plantas regulan las comunidades de hongos, la planta reduce o aumenta la abundancia de específicos hongos por la acción de exudados antibióticos o por enviar señales químicas que inducen el crecimiento de hongos (Dighton et al. 2005). Los exudados de las plantas (metabolitos secundarios) son críticos en la especialización en asociaciones mutualistas o patogénicos entre las plantas e individuos de especies de microorganismos (Broeckling et al. 2008). Meliani et al. (2012) menciona que la abundancia está muy relacionada con el tipo de suelo, características climáticas, otros microorganismos y comunidades de plantas. Coyne (2000) indica que la composición vegetal afecta a la distribución de las especies de hongos.

Efecto del tipo de cultivo. La vegetación es uno de los factores importantes en la diversidad de especies (Garbeva et al. 2004). El mayor impacto de la agricultura sobre estos microorganismos está en sus actividades, que al reducir sus poblaciones, causa un efecto negativo en los parámetros físicos, químicos y biológicos del suelo (Altieri 1999). No obstante Winterhoff (1992) menciona que los cultivos manejados en rotación no tienen un mayor efecto en la diversidad y abundancia de hongos, sin embargo los monocultivos provoca el incremento de la abundancia de ciertas especies de hongos. Posiblemente algunos cultivos favorecieron a los ciertas especies de hongos como es el caso de suelos con cultivo de papa y cebada o disminuidos como el caso del cultivo de quinua por el tipo del manejo aplicados del 
cultivo. Así mismo la abundancia de hongos está entre los 0 a $10 \mathrm{~cm}$ del suelo y baja con la profundidad, materia orgánica y alimentos disponibles (Paul 2007), si las tomas de muestra fueron a una profundidad media de $10 \mathrm{~cm}$, esta podría explicar altas UFC's.

Hongos del suelo. Descripción de hongos filamentosos, el número de aislamientos de hongos desde los suelos difieren por la técnica empleada. Warcup 1950, Bills et al. 2004, señalan que las técnicas benefician o desfavorecen a ciertas especies de hongos, por ejemplo, la dilución favorece el crecimiento de hongos que forman esporas, mientras placas de suelo e inoculación directa favorecen el desarrollo a través del micelio del hongo.

El aislamiento a cultivos puros de las colonias de hongos fue dificultoso por la técnica de placas de suelo, ya que muchas colonias estaban encajadas en el medio de cultivo, a consecuencia no se aislaron todas las colonias de hongos. En este trabajo 44 especies de hongos filamentosos fueron aislados desde los suelos del agroecosistema de K'iphak'iphani, géneros de Penicillium predominaron en los aislamientos y podría deberse a que estos hongos predominan en climas templados, no obstante los hongos son regulados por la cantidad y calidad del sustrato (Paul 2007). Este estudio fue uno de los primeros en evaluar la diversidad de forma exploratoria, suponíamos encontrar baja diversidad por el clima (frio) (Coyne 2000) y por un número escaso de medios y métodos empleados en el aislamiento (Watanabe 2010), sin embargo 44 especies podría indicar una alta diversidad de hongos en esta región, siendo necesario otros estudios para evaluar la biodiversidad de hongos del suelo.

Identificación de hongos filamentosos. La dificultad de la identificación taxonómica de hongos es alta, por lo cual muchas especies de hongos no se identi- ficaron. Muchos factores afectan en el crecimiento y esporulación del hongo en laboratorio (Kirk et al. 2008). Barnett \& Hunter (1998) señalan que muchos hongos imperfectos requieren ciertas condiciones como: luz, humedad, temperatura, $\mathrm{pH}$, nutrientes y vitaminas para sobrevivir, crecer y reproducirse.

La gran diversidad de hongos filamentosos encontrados fue de la división Ascomycota, siendo Penicillium los más frecuentes, por otro lado se encontró mayor número de especies de hongos en suelos naturales y con vegetación nativa, sin embargo algunas especies solo se presentan en un determinado lugar.

El tipo de uso del suelo afecta la distribución de especies de hongos filamentosos. Rojas-Gutiérrez (2014) reporto hongos Beauveria brongniartii y Metarhizium anisopliae por el sector de Viacha, aislados desde insectos, sin embargo estos géneros no fueron aislados en esta investigación. Se halló Trichoderma, que es un micoparásito de otros hongos y se emplea como controlador de Rhizoctonia solani, un hongo fitopatógeno (Paul 2007).

Acorde con este trabajo, se obtuvieron más aislamientos del genero Penicillium y coincidiendo con Paul (2007), el cual indica que este género es abundante en temperaturas y climas fríos, característico de la zona altiplánica de Bolivia. Por otra parte la cantidad de materia orgánica y alimentos disponibles en los suelos también podrían influir en su distribución.

\section{Relaciones}

Relaciones entre el \%MO, pH y textura con la abundancia de hongos. De acuerdo con Meliani et al. (2012) en otro tipo de ecosistema tropical, encontró que la relación entre la abundancia de hongos y la materia orgánica es poca significativa $(r=$ 0.27 ), esto es por el hecho de que cualquier porción de materia orgánica añadida fue asimilada por los 
microorganismos rápidamente especialmente por agentes patógenos. Sin embargo a pesar de la mayor cantidad de MO en suelos naturales del agroecosistema, hay una relación débil entre el contenido de MO y UFC's. Del mismo modo la abundancia está muy relacionada con otros factores como; el tipo de suelo, características climáticas, otros microorganismos y comunidades de plantas (Meliani et al. 2012).

La abundancia de hongos no indica una relación constante con el pH del suelo, más al contrario son débiles (Rousk et al. 2010). Lauber et al. (2008) correlaciono algunas propiedades del suelo con comunidades microbianas, encontró una correlación débil (0.15) entre el pH y abundancia de hongos. Los hongos toleran un amplio rango de $\mathrm{pH}$ (5 a 9) sin impedir su desarrollo (Rousk et al. 2010), sin embargo algunos hongos muestran preferencia por ciertos valores de $\mathrm{pH}$, (Winterhoff 1992). El pH afecta la solubilidad de nutrientes, Lauber et al. (2008), indica que la abundancia está más relacionada por el $\mathrm{P}$ (0.54). Sin embargo esta investigación, muestra resultados contradictorios, aunque el rango de $\mathrm{pH}$ no presenta extremos, es neutro a ligeramente alcalino y muchos nutrientes están disponibles en ese rango (Lavelle \& Spain 2001). Por lo tanto podrían existir otros factores que regulan la abundancia de hongos.

Entre las relaciones de textura del suelo, Meliani et al. (2012) encontró relaciones no significativas ( $\mathrm{p}>$ 0.05 ) entre la abundancia de hongos y actinomicetos con la textura del suelo, también menciona que la textura del suelo influye significativamente en la biomasa del suelo, pero solo es importante de acuerdo al régimen climático.

En este trabajo se encontró una relación débil entre la abundancia de hongos y la textura del suelo. El uso del suelo afecta a las propiedades del suelo y 23 consecuentemente a la diversidad microbiana, los microorganismos no solo son afectados por factores ambientales sino también por factores abióticos (Dixon \& Tilston 2010).

Finalmente, las propiedades físicas (textura), químicas ( $\mathrm{pH}, \mathrm{CE}$ y \% MO) y diversidad de plantas fueron afectadas por el tipo de uso de suelo, tipo de vegetación nativa y tipo de cultivo.

La abundancia y la diversidad hongos filamentosos en los suelos del agroecosistema de K'iphak'iphani están influenciados por el tipo de uso del suelo, tipo de vegetación nativa y tipo de cultivo. Destacar que en los suelos naturales y de vegetación nativa se encuentran mayor diversidad de hongos, sin embargo no presentaron abundancia, contrariamente ocurre en los suelos con cultivos donde existe abundancia pero no diversidad.

La diversidad de hongos filamentosos aislados en cultivos puros y en medio PDA fue 44 especies, estos son registrados por primera vez desde los suelos de un agroecosistema del altiplano del estado Plurinacional de Bolivia.

Las 44 especies de hongos filamentosos, el género Penicillium fueron los más abundantes (8 especies), seguido de Alternaría (3 especies) Rhizopus y Mucor (1 especie), Fusarium (1 especie) y Trichoderma (1 especie), los 29 restantes no fueron identificados por dificultades técnicas, métodos de genética molecular podrían identificar la diversidad de hongos del suelo.

Las relaciones entre \%MO vs UFC's fue negativa $\left(r^{2}=32.1\right)$. Por otro lado si hubo una relación fuerte $\left(r^{2}=47.7\right)$ entre $\mathrm{pH}$ y UFC's. Mientras para porcentaje de Arena y UFC's presentaron relaciones débiles $\left(r^{2}=8.6\right)$. 


\section{Conflictos de intereses}

Los autores han cumplido las normas éticas de publicación, y no generan conflictos de interés en la presente investigación.

\section{Agradecimientos}

Los autores agradecen a la Fundación PROINPA regional altiplano, al Centro Experimental K'iphak'iphani y al personal técnico por la colaboración en los laboratorios de investigación en microbiología de suelos.

\section{Literatura citada}

Altieri MA. The ecological role of biodiversity in agroecosystems. Agric Ecosyst Environ. 1999; 74: 19-31.

Arias-Mota RS, Heredia-Abarca G, Mena-Portales J, Sivila R. Primeros registros de hongos anamorfos (Hyphomycetes) colectados en restos vegetales del parque nacional Cotapata, La Paz, Bolivia. Bol Soc Micol Madrid. 2007; 31: 157-169.

Barnett HL, Hunter BB. Illustrated Genera of Imperfect Fungi. APS Press, Minnesota, USA, 1998. p. 218.

Bills GF, Christensen M, Powell M, Thorn G. Saprobic soil fungi. p. 271-302, In G.M. Mueller, G.F. Bills, and M.S. Foster (Eds.). Biodiversity of Fungi: Inventory and Monitoring Methods. Elsevier Academic Press, San Diego, CA. 2004. p. 777.

Broeckling CD, Broz AK, Bergelson J, Manter DK, Vivanco JM. Root exudates regulate soil fungal community composition and diversity.
Appl Environ Microbiol. 2008; 74(3): 738744.

Cabello M, Arambarri A. Diversity in soil fungi from undisturbed and disturbed Celtis tala and Scutia buxifolia forests in the eastern Buenos Aires province (Argentina). Microbiol Res. 2002; 157(2): 115-125.

Carlile MJ, Watkinson SC, Gooday GW. The Fungi. 2nd ed. London: AP. 2001. p. 588.

Christensen M. Soil microfungi of dry to mesicconifer-hardwood forests in northern Wisconsin. Ecology. 1969; 22:9-27.

Coyne M. Microbiología del Suelo: Un Enfoque Exploratorio. Ed. Paraninfo. España. 2000. p. 416.

DeFries RS, Foley JA, Asner GP. Land-use choices: balancing human needs and ecosystem function. Front Ecol Environ. 2004; 2(5): 249-257.

Diaz R, Gamazo C, López-Goñi I. Manual práctico de microbiología. 2a ed. Barcelona, España. Masson SA. 1999. p. 208.

Dighton J, White JF, Peter O. The Fungal Community: Its Organization and Role in the Ecosystem. 3rd ed. CRC Press, Boca Ratón. 2005.

Dixon GR, Tilston EL. Soil microbiology and sustainable crop production. Ed. Springer Science and Media BV. Dordrecht, The Netherlands. 2010. p. 451.

Domsch KH, Gams W, Anderson T. Compendium of soil fungi, vol. I. Academic, London. 1980. p. 859.

Flanagan PW. Fungal taxa, physiological groups and biomass: a comparison between ecosystems. In The fungal community, D. T. Wicklow, and G. C. Carroll (eds.). Marcell Dekker, Nueva York. 1981. p. 569-592.

Garbeva P, Van Venn JA, Van Elsas JD. Microbial diversity in soil: selection microbial popula- 
tions by plant and soil type and implications for disease suppressiveness. Annu Rev Phytopathol. 2004; 42 (29): 243-270.

Gobierno Autónomo municipal de Viacha. Plan de desarrollo municipal Viacha 2012-2016. 2012. p. 476.

Kirk PM, Cannon PF, Minter DW, Stalpers JA. Ainsworth \& Bisby's dictionary of the fungi. 10a. ed. CABI. Wallingford, UK. 2008. p. 771. Lauber CL, Strickland MS, Bradford MA, Fierer N. The influence of soil properties on the structure of bacterial and fungal communities across land-use types. Soil Biol Biochem. 2008; 40(9): 2407-2415.

Lavelle P, Spain AV. Soil ecology. Dordrecht, NL. Kluwer Academic Publishers. 2001. p. 654.

Meliani A, Bensoltane A, Mederbel K. Microbial diversity and abundance in soil: related to plant and soil type. Am J Plant Nutr Fert Technol. 2012; 2: 10-18.

Moreira FMS, Siquiera JO. Os organismos do solo. In: Microbiologia e Bioquimica do Solo. 2nd ed. Lavras. 2006; 17-82. UFLA.

Paul EA. Soil Microbiology, Ecology, and Biochemistry. 3rd ed. Burlington, US. AP. 2007. p. 514.

Rojas-Gutiérrez RL. Capacidad biocontroladora de (Beauveria brongniartii Sacc.) y (Metarhizium anisopliae Metsch.) en el control de pulgones Macrosiphum euphorbiae (Hemiptera: Aphididae). [Tesis de Licenciatura]. Universidad Católica Boliviana San Pablo. La Paz. Bolivia. 2014. p. 62.

Rousk J, Bååth E, Brookes PC, Lauber CL, Lozupone C, Caporaso JG, et al. Soil bacterial and fungal communities across a $\mathrm{pH}$ gradient in an arable soil. ISME J. 2010; 4(10):1340-1351.
Samson RA, Visagie CM, Houbraken J, Hong S-B, Hubka V, Klaassen CHW, et al. Phylogeny, identification and nomenclature of the genus Aspergillus. Stud Mycol. 2014 78: 141-173.

Sivila de Cary R, Angulo W. Efecto del descanso agrícola sobre la microbiota del suelo (Patarani-Altiplano central boliviano). Ecología en Bolivia. 2006; 41(3): 103-115.

Sivila R, Hervé D. Análisis de la microbiota en suelos cultivados del Altiplano central. Primer Congreso Boliviano de la Ciencia del Suelo. La Paz, Bolivia. Julio 1999. p. 5-14.

Swift MJ, Bignell D. Standard methods for the assessment of soil biodiversity and land-use practice. ASB-Lecture Note 6B. International Centre for Research in Agroforestry, South East Asian Regional Research Programme, Bogor, Indonesia. 2001.

Vieira FC, Nahas E. Comparison of microbial numbers in soils by using various culture media and temperatures. Microbiol Res. 2005; 160(2): 197-202.

Warcup JH. The soil-plate method for isolation of fungi from soil. Nature. 1950; 166: 117-118.

Watanabe T. Pictorial Atlas of Soil and Seed Fungi: morphologies of cultured fungi and key to species. Boca Raton: CRC Press. 2010. p. 397.

Webster W, Weber RWS. Introduction to Fungi. 3rd ed. Cambridge, UK. Cambridge University Press. 2007. p. 841.

Winterhoff W. Fungi in vegetation science. Springer Science Business Media Dordrecht. 1992.

Zak DR, Holmes WE, White DC, Peacock AD, Tilman D. Plant diversity, soil microbial communities, and ecosystem function: are there any links? Ecology. 2003; 84(8): 2042-2050. 